\title{
Die \\ Resorption der Fette vollzieht sich dadurch, dass sie in wässrige Lösung gebracht werden.
}

Von

\section{E. P r $\mathbf{i} g$ er.}

Inhalt.

Seite

$\$$ 1. Einleitung. Es scheint, als ob die das Fett lösenden Kräfte der Verdauungswerkzenge zur Erklärung der Fettresorption nicht genügter . . . . . . . . . . .

\$ 2. Ueber die Bedentung der Galle für die Verseifung der Oelsäure . . . . . . . . . . . . . . . . . . 2

$\$ 3$. Versuche über die Löslichkeit und Verseifbarkeit der Caprylsäure, Palmitinsäure und Stearinsäure . . . . . . . 11

$\$$ 4. Veber die Unlöslichkeit des Neutralfettes in Galle . . . 28

$\$$ 5. Ueber die Zustände in Wasser gelöster Seifen . . . . . 29

$\$$ 6. Ueber die Reaction dep Flüssigkeit im Dünndarm. • . . 33

\$ 7. Erklärung der Fettresorption auf Grund der gewonnenen Ergebnisse. . . . . . . . . . . . . . . . 41

\$ 8. Ergebnisse . . . . . . . . . . . . . . . 46

$\$$ 1. Einleitung. Es scheint, als ob die das Fett lösenden Kräfte der Verdauungswerkzenge znr Erklärung der Fettresorption nicht genügten.

Es sind keine Thatsachen bekannt, welche uns berechtigten, den eigentlichen Fetten als solchen Löslichkeit in den Säften der Verdaungswerkzeuge zuzuschreiben.

Gleichwohl ist sicher bewiesen, dass in den wässrigen Verdauungssäften Fette in Lösung gebracht werden. Nach Allem, was bekannt ist, geschieht dies aber nur, nachdem das Fett unter der Einwirkung verschiedener Enzyme und Fermente gespalten wurde in das wasserlösliche Glycerin und die in Wasser unlösliche Fettsäure.

E. Ptlüger, Archiv für Physiologie. lid. 86. 
Die Fettsäuren verbinden sich mit dem Natron der kohlensauren und gallensauren Salze der Verdauungssäfte zu Seifen, d. h. in Wasser löslichen Verbindungen.

Andererseits sind die Fettsäuren als solche in Galle thatsächlich löslich.

Auf den ersten Blick scheint es, als ob diese lösenden Kräfte viel zu gering seien, um die Vorstellung zuzulassen, dass alles Fett vor der Resorption in wasserlösliche Stoffe umgewandelt werde. Denn einmal soll nicbt genug Alkali für die Verseifung zur Verfügung stehen, und andererseits genügt die Löslichkeit der Fettsäuren auch nicht zur Erklärung der thatsächlichen Grösse der Fettresorption.

\section{§ 2. Ueber die Bedeutung der Galle für die Verseifung der 0elsäure.}

Bei Versuchen, die ich über die Verseifungsgeschwindigkeit von Oelsäure durch eine wässrige Sodalösung von $37^{\circ} \mathrm{C}$. anstellte, überraschte mich die ausserordentliche Langsamkeit dieses Vorganges. Denn wenn ich äquivalente Mengen von Oelsäure und wässriger Sodalösung bei der genannten Temperatur acht Tage lang erwärmte, reagirte die Flüssigkeit noch alkalisch, und das Mikroskop zeigte eine reichliche Fmulsion von Fettsäuren. Diese auffallende Langsamkeit der Verseifung steht in Widerspruch mit der Schnelligkeit der Fettresorption, wenn diese die Lösung der Fette als Seifen voraussetzt. - Aber sogar wässrige verdünnte Kalilauge wird mit Oelsäure selbst beim Kochen nur sehr langsam und unvollständig verseift.

Indem ich in Erwägung zog, dass eine alkoholische Lösung von Fettsäure mit einer ebensolchen von Alkali beim Erwärmen sofort zu vollkommener Verseifung führt, zweifelte ich nicht, dass jene von mir beobachtete Langsamkeit dieses Vorganges ihren Grund darin habe, dass die Oelsäure sich mit einer Sodalösung zwar emulsionirt, aber nicht mischt.

Wenn nun wirklich Galle Fettsäuren in Lösung bringt, so wäre die Bedingung verwirklicht, die Lösung der Fettsäuren mit der der Soda mischbar zu machen, weil es sich in beiden Fällen um wässrige Lösungen handelt. Wie bei der raschen Verseifung in alkoholischer Kalilauge müsste also Fettsäure mit dem Alkali bei Gegenwart von Galle schnell verseift werden. 
Versuch 1 .

Es war wünschenswerth, eine genauere Vorstellung zu erhalten von der Langsamkeit der Verseifung, wenn Oelsäure mit einer äquivalenten Menge verdünnter wässriger Sodalösung bei $37^{\circ} \mathrm{C}$. zusammen erwärmt wird.

$95 \mathrm{cem}^{1}$ ) einer einprocentigen Sodalösung,

$5 \mathrm{~g}(5,5 \mathrm{ccm})$ Oelsäure,

$50 \mathrm{cem}$ Wasser

werden in ein Kölbchen gegeben und bei $37^{\circ} \mathrm{C} .24$ Stunden erwärmt.

Durch Ausschütteln mit Aether bis zur vollkommenen Ersehöpfung wiedergefunden: 4,132 g. Oelsäure; verseift also: 0,868 g Oelsäure. Von $100 \mathrm{~g}$ Oelsäure sind also nur $17,3 \%$ verseift worden.

Um etwaige Bedenken zu beseitigen, welche gegen mein Verfahren, nach dem ich freie Oelsäure und Seife bestimmte, vorgebracht werden könnten, will ich einen Versuch beschreiben, mit Hülfe dessen man sich auch ohne quantitative Analyse von der Richtigkeit des hauptsächlichsten Theiles der gemeldeten Thatsachen leicht überzeugen kann.

Wenn man wie bei dem beschriebenen Versuch die Oelsäure mit der Sodalösung gemischt hat und ein wenig schüttelt, erhält man eine weisse Milch in Folge der Emulsionirung der Oelsäure. Ziemlich bald steigt die weisse Enulsion zur Olerfläche empor, wo viele kleinere und grössere weisse Flocken sich bemerkbar machen. Häufiges Schütteln hat immer wieder denselben Erfolg, und so bleibt es, wenn man den Versuch auch 24 Stunden fortsetzt. Eine wesentliche Aenderung in dem äusseren Ansehen der Emulsion ist innerhalb 24 Stunden also nicht zu sehen. Bringt man die weissen Flocken unter das Mikroskop, so erkennt man, dass sie aus einer Anhäufung zahlloser Tropfen bestehen, die genau wie Fetttropfen aussehen. Schüttelt man die Emulsion mit Acther, so verschwinden die weissen Flocken schnell und, beim Verdunsten des Aethers hinterbleibt Oelsäure. Fs ist also ganz unzweifelhaft, dass Oelsäure-Emulsion in einer äquivalenten Sodalösung sich nur sehr langsam verseift und annähernd indifferent gegen diese verhält. Dass aber immerhin eine geringe Seifenbildung stattfindet, erkennt man

1) Streng genommen genügen $94 \mathrm{ccm}$. Ich wählte aber $95 \mathrm{ccm}$, um den Benetzungsfehler auszugleichen, da ich aus einem schmalen, graduirten Standcylinder abmass. 
an dem beim Schütteln auftretenden Seifenschaum und an der Fällung einer weissen, gallertigen Substanz beim Ausschütteln mit Aether.

Die mitgetheilten Erfahrungen waren wünschenswerth, weil ein Bedenken gegen die von mir angewandte analytische quantitative Methode vorhanden zu sein scheint.

Die Natronseife der Oelsäure ist in 100 Theilen siedenden Aethers löslich und möglicher Weise auch in kaltem Aether nicht ganz unlöslich, zumal wenn ein Gemenge von freier Oelsäure und öIsaurem Natrium mit Aether ausgeschüttelt werden soll. Es ergibt sich aber, dass bei oft wiederboltem Ausschütteln der Aetherextract zuletzt beim Verdunsten fast nichts mehr hinterlässt. Man beobachtet höchstens einen unwägbaren Hauch. - Sobald man dann die ausgeschüttelte Seifenlösung nach Verjagung des Aethers mit verdünnter Schwefelsäure versetzt, häuft sich die flüssige Oelsäure über der wässrigen Flüssigkeit wieder an. Die Löslichkeit der Natronseife der Oelsäure in kaltem Aether ist also so gering, dass daraus für diese Untersuchungen kein Fehler erwächst.

\section{Versuch 2.}

Es sollte nochmals die auffallende Thatsache geprüft werden, dass bei Mischung äquivalenter Mengen von Oelsäure und wässriger Sodalösung eine so geringe Verseifung eintritt.

$95 \mathrm{ccm}$ Sodalösung von $1 \%$,

50 cem Wasser,

$5 \mathrm{~g}$ Oelsäure.

Sieben Stunden bei $37^{\circ} \mathrm{C}$. erwärmt.

Milchweisse Emulsion beim Umschütteln bildend, so dass sicher ein grosser Theil der Oelsäure nicht gelöst ist.

Durch Ausschütteln mit Aether wird

wiedergefunden . 4 4,050 g Oelsäure,

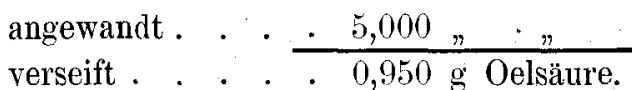

Von $100 \mathrm{~g}$ Oelsäure sind also

verseift $19 \%$ Oelsäure,
unverändert $81 \%$

Versuch 3.

Wir wollen nunmehr die soeben beschriebenen Verseifungsversuche wiederholen, nur mit dem Unterschied, dass die Mischung statt mit Wasser vermischt wird mit einem gleichen Volum schwach angesäuerter Galle. Die Versuchsbedingungen waren folgende: 
$5 \mathrm{~g}$ Oelsäure im Kolben abgewogen,

$95 \mathrm{ccm}$ Sodalösung von $1 \%$, also die der angewandten Oelsäure äquivalente Menge,

$50 \mathrm{ccm}$ sehr schwach mit $\mathrm{ClH}$ angesäuerte Ochsengalle.

Sofort entsteht eine feine weisse Emulsion. Obwohl nicht erwärmt wurde, ist nach ${ }^{1 / 2}$ Stunde die Flüssigkeit durchsichtig, weil sich die Oelsäure gelöst hat.

Es wird 24 Stunden bei $37^{\circ} \mathrm{C}$. erwärmt und eine vollkommen durchsichtige Flüssigkeit erhalten.

Der Versuch beweist, dass $100 \mathrm{~g} \mathrm{sehwach}$ angesäuerte Galle bei Gegenwart einer ausreichenden Menge von Soda $10 \mathrm{~g}$ Oelsäure in Lösung überführten. Wieviel Seife gebildet wurde, ist natürlich unbekannt. Denn die beabsichtigte Ausschüttelung mit Aether verunglückte.

Beim Schütteln der Flüssigkeit entstand sofort Seifenschaum. Auffallend war, dass die Flüssigkeit fast gar keine Opalescenz zeigte, da wässrige Seifenlösungen zu opaleściren pflegen.

Auffallend ist ferner, wie sehr in diesem Versuche die Lösungskraft der mit Soda versetzten Galle den von Moore und Rockwood für die Oelsäure gefundenen Werth von $4-5 \% \%$ übertrifft. Und offenbar ist der von mir beobachtete Werth ein Minimalwerth.

Ich kann die hier mitgetheilten Versuche als Vorlesungsversuche empfehlen, und zwar in folgender Form: Man nimmt zwei gleiche Glaskölbchen von etwa $200 \mathrm{cem}$ Inhalt und füllt in

$$
\begin{aligned}
& \text { Kolben I Kolben II } \\
& 5,5 \mathrm{ccm} \text { Oelsäure, } \quad 5,5 \mathrm{ccm} \text { Oelsäure, } \\
& 95,0 \text { "Sodalösung von } 1{ }^{\%}, 0,95,0 \text { "Sodalösung von } 1^{0} \\
& 50,0 \text { "Wasser. } 50,0 \text { \#chsengalle. }
\end{aligned}
$$

Man schüttelt beide mehrmals. Alsbald wird der Inhalt von Kolben II seine weisse Farbe verlieren und durchsichtig werden, während der von Kolben I weisse Mileh enthält und dauernd undurchsichtig bleibt.

Es musste nun untersucht werden, wesshalb die Galle die Fettsäure bei Gegenwart von Soda so kräftig in Lösung bringt.

$$
\text { Versuch } 4 \text {. }
$$

95 cem Sodalösung von $1 \%$

$50 \mathrm{cem}$ der bisher angewandten schwach sauren Ochsengalle,

$5 \mathrm{~g}$ Oelsäure. 
Die anfangs vorhandene weisse Emulsion verschwindet schnell. Trotzdem wird die Emulsion sieben Stunden bei $37^{\circ}$ erwärmt.

Durch Ausschütteln mit Aether erhalten: 4,5422 g Oelsäure.

$50 \mathrm{ccm}$ derselben Galle, die nicht mit Oelsäure und Soda vermischt war, wurden auch mit Aether ausgeschüttelt und ergaben:

$0,0705 \mathrm{~g}$ Extract (fast ganz krystallinisch).

Folglich muss dieser Werth von der erhaltenen Oelsäure abgezogen werden:

Rohe Oelsäure • . . . . 4,5422 g, ab präformirter Aetherextract . 0,0705,

$$
4,4717 \mathrm{~g} \text { Oelsäure. }
$$

Die wiedergefundene Oelsäure wurde nun mit alkoholischer Kalilauge verseift, und die Ausschüttelung der gebildeten Seife ergab nur $0,0237 \mathrm{~g}$ Aetherextract. Die Ansäuerung der in wässrige Lösung gebrachten Seife hatte die Ausscheidung der Oelsäure zur Folge, die sich als klares Oel auf der Oberfläche ansammelte.

Also angewandt . . . . $5,000 \mathrm{~g}$ Oelsäure,
unverseift wiedergefunden $4,4717 \mathrm{n} n$
Verseift . . . . . . $\quad 0,5283$ g Oelsäure.

Das merkwürdige Ergebniss besteht also darin, dass entgegen unserer Erwartung die Galle in keiner Weise die Verseifung der Oelsäure begünstigt hat. Und ebenso ist trotzdem entgegen unserer Erwartung ein auffallend grosser Theil der Oelsäure in Lösung gegangen, obwohl derselbe nicht verseift worden ist.

$100 \mathrm{ecm}$ Galle haben bei Gegenwart von Soda $10 \mathrm{~g}$ Oelsäure gelöst und $\mathrm{zwar} 8,943 \mathrm{~g}$ als unverseifte Oelsäure, oder von 100 Theilen Oelsäure sind 89,143 Theile gelöst und nur 10,57 verseift.

Der hier von mir beobachtete Löslichkeitscoëfficient übertrifft den von Moore und Rockwood gemeldeten um mehr als das Doppelte.

\section{Versuch 5 .}

Bisher wurde die Galle schwach angesäuert. Jetzt soll sie unverändert zur Anwendung kommen, nachdem sie nur filtrirt worden war. Ochsengalle reagirt dann immer bald mehr, bald weniger 
alkalisch und ist oft dünnflüssig, wenn auch stets etwas fadenziehend, zuweilen aber so dick und steif, dass man sie nicht filtriren kann.

$95 \mathrm{ccm}$ Sodalösung von $1 \%$;

$5,0 \mathrm{~g}$ Oelsäure;

$50,0 \mathrm{ccm}$ alkalische Ochsengalle $(50 \mathrm{cem}$ dieser Galle brauchten 2,5 cem einer ClH-Lösung von 2,2\% zur Neutralisation).

Weisse Emulsion erhalten, die 23 Stunden bei $37^{\circ} \mathrm{C}$. erwärmt wird.

Die Emulsion ist verschwunden; die Lösung ist klar und durchsichtig. Durch Ausschütteln mit Aether wird erhalten:

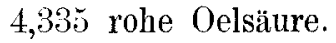

$50 \mathrm{ccm}$ derselben Galle lieferten 0,0228 $\mathrm{g}$ Aetherextract, folglich:

$$
\begin{aligned}
& +4,395 \\
& -0,0228 \\
& \hline
\end{aligned}
$$

Wiedergefunden $4,3122 \mathrm{~g}$ Oelsäure.

Demnach $100 \mathrm{ecm}$ alkalische Ochsengalle haben gelöst . . . 8,624 g Oelsäure, verseift . . . 1,376,

Oder auf $100 \mathrm{~g}$ angewandter Oelsäure werden gelöst . . . 86,24\%, verseift . . . 13,76\% 0.

Versuch 6.

$95 \mathrm{cem}$ Sodalösung von $1 \%$,

$50 \mathrm{ccm}$ frische, filtrirte, sehr klare, grüne Ochsengalle, mit $\mathrm{ClH}$ neutralisirt: Spur saurer Reaction. $100 \mathrm{ccm}$ dieser Galle brauchten $3,43 \mathrm{~cm}$ ClH von $2,2 \%$,

$5 \mathrm{~g}$ Oelsäure.

Nach Erwärmung der Mischung drei Stunden bei $37^{\circ} \mathrm{C}$. ist die weisse Emulsion vollkommen versehwunden. Die Flüssigkeit ist in einer Schicht von mehreren Centimetern vollkommen durchsichtig. Unter dem Mikroskop ist ebenfalls nur hier und da ein kleines Tröpfchen zu sehen.

Durch Ausschütteln mit Aether wird gefunden 4,785 g Extract

Hiervon geht $a b$ der in $50 \mathrm{cem}$ dieser Galle enthaltene präexistirende Aetherextract . • • $\frac{0,037 \mathrm{~g}}{4,748 \mathrm{~g} \text { Oelsäure }}$

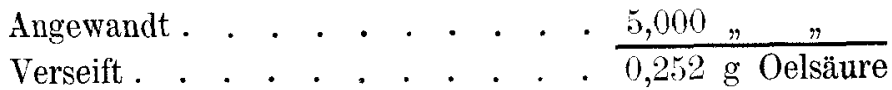


Also $100 \mathrm{ccm}$ Galle haben gelöst . . . 9,496 g Oelsäure, verseift . . 0,404, " "

Oder von $100 \mathrm{~g}$ Oelsäure wurden gelöst. . . $94,96 \mathrm{~g}$ Oelsäure, verseift . . 5,04" "

Versuch 7 .

Es soll auf dieselbe Menge von Galle weniger Fettsäure mit der äquivalenten Sodalösung benutzt werden.

76 cem Sodalösung von $1 \%$,

$50 \mathrm{ccm}$ Galle, neutral. Spur saurer Reaction,

4 g Oelsäure.

Weisse Emulsion, die beim Erwärmen bald verschwindet; denn 2 Stunden nach Mischung ist die Lösung ganz durchsichtig. Erwärmung dauert bei $37^{\circ}$ C. 19 Stunden.

Durch Ausschütteln erhalten . . . . 3,643 g Aetherextract, Hiervon ab präexistirend . . . . . $\frac{0,037,}{3,606 \mathrm{~g} \text { Oelsäure }}$ Verseift . . . . . . . . . 0,394, "

100 cem Galle haben also gelöst . . . 7,212 g Oelsäure, verseift . . 0,788,"

Oder von $100 \mathrm{~g}$ Oelsäure wurden gelöst . . . . . . 90,1\%, verseift. . . . . . $9,9 \%$

Versuch 8. (Qualitativ.)

Es soll noch ein Mal untersucht werden, ob ohne Galle die Fmulsion von Oelsäure mit einer äquivalenten Menge von Sodalösung nicht verschwindet.

$76 \mathrm{ccm}$ Sodalösung von $1 \%$,

50 ccm Wasser,

$4 \mathrm{~g}$ Oelsäure.

Gibt sofort eine weisse, grobflockige, undurchsichtige Emulsion. Bei $37^{\circ}$ C. 24 Stunden erwärmt. Die weisse, grobflockige Emulsion ist nicht verschwunden.

Es wurden nun $50 \mathrm{ccm}$ Galle hinzugefügt. In 3 Stunden ist fast Alles gelöst. 
Also ohne Galle findet keine erhebliche Lösung der Fettsäure statt.

\section{Versuch 9. (Qualitativ.)}

Da nun Moore und Rockwood; welche die Löslichkeit der Fettsäuren in Galle untersuchten, so sehr viel kleinere Werthe als ich erhielten, muss festgestellt werden, ob der von mir eingeführte Zusatz von Soda wesentlich ist, obwohl die Soda mit Galle nicht stärker verseifend auf Oelsäure wirkt.

95 cem Wasser (statt Sodalösung),

$50 \mathrm{ccm}$ Galle, neutral. Spur saurer Reaction,

$4 \mathrm{~g}$ Oelsäure.

Es entsteht eine weisse Emulsion. Die Mischung wird 24 Stunden bei $37^{\circ}$ C. erwärmt. Die Emulsion bleibt aber und häuft sich als obere Schicht in gröberer Emulsion an. Bei oft wiederholtem Schütteln entsteht immer wieder dieselbe weisse Milch; bald steigt das Fett auf die Oberfläche und obwohl der Versuch 24 Stunden fortgesetzt wird, bleibt es dabei.

Es ist also gewiss, dass Gegenwart, sowohl von Galle als von Soda erst die starke Lösung der Oelsäure bedingt. Wunderbar ist dabei, dass die ausserordentliche Beihülfe, welche die Soda der Galle leistet, gar nicht dadurch bedingt ist, dass die Soda durch Verseifung löst. Denn Aether entzieht ja die gelöste Oelsäure der Mischung vollständig. Ehe wir an eine Frklärung der räthselhaften Thatsache herantreten, wird es richtig sein, den Kreis der Frfahrungen noch mehr zu erweitern.

Mir scheint die hier gefundene Thatsache desshalh von grosser Bedeutung, weil man bisher glaubte, dass die Soda der Verdauungssäfte die Resorption der Fette durch Verseifung ermögliche. Indem man voraussetzte, dass die Menge der von dem Verdauungsapparat gelieferten Soda nicht entfernt zur Verseifung des resorbirten Fettes ausreiche, folgerte man, dass durch Verseifung die Resorption der Fette nicht genügend erklärbar sei. - Wir sehen jetzt, dass die Soda bei Gegenwart von Galle die Oelsäure löst, ohne dass die Soda dabei verbraucht wird.

\section{Versuch 10 .}

Es schien mir zunächst von Belang, festzustellen, ob etwa die durch die Soda bedingte Wegnahme gewisser freier Säuren in Betracht käme, oder ob eine Beziehung zwisehen der Menge der Soda 
und der gelösten Fettsäure zu erkennen sei. Folgende Anordnung wurde desshalb getroffen:

50 cem Galle, neutral,

10 "Sodalösung von $1 \%$,

$4 \mathrm{~g}$ Oelsäure,

$85,6 \mathrm{ccm}$ Wasser.

Weisse Emulsion. Erwärmt vier Stunden bei $37^{\circ} \mathrm{C}$. Weil noch viele ungelöste Flocken da sind, werden noch $30 \mathrm{ccm}$ Sodalösung von $1 \%$ hinzugefügt; nach drei Stunden ist die Emulsion noch nicht verschwunden; ich erwärme weiter bis zum folgenden Tag, nachdem ich noch $20 \mathrm{ccm}$ Sodalösung hinzugefügt habe. Nach 24 Stunden ist noch immer viel ungelöste Fettsäure vorhanden. Ich setze noch $26 \mathrm{ccm}$ Sodalösung von $1 \%$ hinzu; also ist jetzt die äquivalente Menge vorhanden. Nachdem nun nochmals 24 Stunden erwärmt wurde, ist der grösste Theil der Emulsion verschwunden. Die Flüssigkeit ist ganz durchsichtig; es schwimmen aber noch einige Flöckchen in derselben. Die lange Dauer des Versuches hat dies wohl verschuldet. Jedenfalls zeigt diese Erfahrung, dass die Galle das Maximum der ihr zugesetzten Oelsäure erst dann in Lösung überführt, wenn man eine chemisch annähernd äquivalente Menge Soda hinzugefügt hat.

Für die genauere Beurtheilung des mitgetheilten Versuches war es noch von Belang, festzustellen, ob die zu der Galle gefügte Soda die Lösung der Fettsäure erst ermöglicht, nachdem eine bestimmte Sodamenge zugefügt ist, oder nachdem der Procentgehalt der Soda in der Mischung einen bestimmten Betrag erreicht hat.

\section{Versuch 11 .}

In den bisher mitgetheilten Versuchen hatte man $95 \mathrm{ccm}$ Sodalösung $+50 \mathrm{ccm}$ Galle $+5,5 \mathrm{ccm}$ Delsäure $=150 \mathrm{ccm}$. Die $95 \mathrm{cem}$ Sodalösung von $1 \%$ enthielten $0,950 \mathrm{~g}$ Soda, die sich in der Mischung von $150 \mathrm{ccm}$ vertheilten. Also enthielt die Mischung $0,633 \%$ Soda.

Demnach wurde folgende Anordnung getroffen:

$50 \mathrm{ccm}$ Galle,

$0,327 \mathrm{~g}$ trockne Soda in der Galle gelöst,

$5 \mathrm{~g}$ Oelsäure hinzugefügt.

Es entstand eine trübe Flüssigkeit, die über Nacht bei $37^{\circ}$ erwärmt wurde. Am anderen Morgen. sind Flocken auf der Oberfläche, 
die beim Schütteln verschwinden. Die Flüssigkeit ist aber durchaus trüb und nicht durchsichtig, wie es bisher bei gleicher Concentration der Sodalösung, aber grösserer absoluter Menge von Soda beobachtet worden ist. - Als ich mehr trockne Soda hinzufügte, erzielte ich auch keine Durchsichtigkeit.

Weil der Inhalt des Dünndarms während der Fettresorption nicht immer alkalisch, sondern auch sauer reagiren kann, worüber später Genaueres mitgetheilt wird, war es nothwendig, zu untersuchen, wie sich die Lösungskraft der Galle für Oelsäure verbält, wenn sie so weit mit Salzsäure schwach angesäuert worden ist, dass die Mischung eben röthend auf Lakmus wirkt. Solche Versuche sind auch von Moore und Rockwood nicht angestellt worden. Sie geben nur an, dass Ochsengalle - das ist also die alkalische Flüssigkeit -4 bis $5 \%$ Oleinsäure zu lösen vermöge. Meine Bestimmungen führten mit der sauren Galle zu genau demselben Werthe.

Fassen wir die mit der Oelsäure erhaltenen Ergebnisse kurz zusammen, so ergab sich:

1. $100 \mathrm{ccm}$ frische, also alkalische Ochsengalle lösen 4 bis $5 \mathrm{~g}$ Delsäure. Denselben Werth liefert neutralisirte oder schwach angesäuerte Galle.

2. $100 \mathrm{ccm}$ Galle, der eine verdünnte Sodalösung zugesetzt wurde, lösen wenigstens 7 bis $10 \mathrm{~g}$ Oelsäure, so aber, dass nur ein kleiner Theil derselben verseift wird.

\section{\$3. Versuche über die Löslichkeit und Verseifbarkeit der Capryl- säure, Palmitinsäure, Stearinsäure.}

Da die Oelsäure zu einer anderen homologen Reihe gehört wie die bei der Resorption auch in Betracht kommende Palmitinsäure und Stearinsäure, musste untersucht werden, ob die letzteren sich ähnlich wie die Oelsäure verhalten.

Um einen Anhaltspunkt zur Beurtheilung zu erbalten, machte ich einen vorläufigen Versuch mit der Caprylsäure, die ebenfalls wie die Oelsäure bei gewöhnlicher Temperatur flüssig und in Wasser unlöslich ist, aber mit der Stearinsäure und Palmitinsäure in dieselbe homologe Reihe gehört.

Versuch 12.

$73,6 \mathrm{ccm}$ Sodalösung von $1 \%$ äquivalent mit $2,0 \mathrm{~g}$ Caprylsäure 50,0 ecm neutralisirte frische Ochsengalle. Spurweise saur Reaction. 
Beim Umschütteln trübe Emulsion, die beim Erwärmen auf $37^{\circ} \mathrm{C}$. in einigen Stunden nahezu und in 24 Stunden vollständig verschwindet, so dass eine klare Lösung vorliegt.

Ich wandte mich nunmehr zur Untersuchung der Palmitinsäure und Stearinsäure.

Da ich gefunden hatte, dass die Oelsäure sich in neutraler, schwach saurer und besonders in durch Soda alkalisch gemachter Galle so reichlich und leicht löst, und da für Caprylsăure dasselbe zu gelten schien, wäre zu erwarten gewesen, dass die Stearinsäure und Palmitinsäure sich ähnlich verhalten würden. Das war aber durchaus nicht der Fall; es traten vielmehr nicht bloss mit Rücksicht auf die Löslichkeit, sondern auch Verseifungsfähigkeit ungewöhnlich bedeutende Unterschiede auf.

\section{Versuch 13}

Da nach Moore und Rockwood $100 \mathrm{cem}$ Galle weniger als 0,5 g Stearinsäure lösen, stellte ich folgenden Versuch an: Im Kölbchen werden abgewogen $0,541 \mathrm{~g}$ Stearinsäure, $200 \mathrm{ccm}$ sehr schwach angesäuerter frischer. Ochsengalle hinzugefügt und 24 Stunden bei $37^{\circ} \mathrm{C}$. erwärmt. Anscheinend hat sich gar nichts von den Krystallen gelöst, die in der oberen Schicht der Mischung schwimmen.

Da also noch nicht $0,270 \mathrm{~g}$ Stearinsäure gelöst wurden, wog ich $0,1525 \mathrm{~g}$ Palmitinsäure ab, fügte $200 \mathrm{ccm}$ frische, schwach angesäuerte Galle zu und erwärmte 24 Stunden auf $37^{\circ} \mathrm{C}$. Scheinbar hat sich abermals nichts gelöst. Also $100 \mathrm{ccm}$ schwach saure Galle lösten noch nicht $0,076 \mathrm{~g}$ Palmitinsäure.

Da es hiernach schien, als ob die festen Fettsäuren in schwach saurer Galle kaum löslich seien, stellte ich noch folgenden Versuch an:

Nachdem ich einige Milligramme Stearinsäure in einem Kölbchen über der Flamme flüssig gemacht, $30 \mathrm{ccm}$ sehr schwach mit $\mathrm{ClH}$ angesäuerte Ochsengalle hinzugegossen und geschüttelt hatte, erschienen alsbald zarte Krystallfitter der Fettsäure, die auch bei Erwärmung auf $37^{\circ} \mathrm{C}$. nicht verschwanden.

Weil Moore und Rockwood angeben, dass $100 \mathrm{~g}$ Ochsengalle weniger als $0,5 \mathrm{~g}$ Stearinsäure oder Palmitinsäure lösen, während es sich bei meinem soeben besehriebenen Versuche nur um gelöste Spuren handeln kann, wiederholte ich den Versuch mit 
frischer Galle, die nicht neutralisirt oder angesänert worden war. Denn die frische alkalische Galle ermöglicht die Entstehung von Seifen und könnte desshalb stärker lösend auf Stearinsäure wirken als neutrale oder angesäuerte Galle.

Ich wog $0,1 \mathrm{~g}$ Stearinsäure im Kölbchen genau ah, goss $100 \mathrm{ccm}$ frisehe alkalische Galle zu, schüttelte und erwärmte 24 Stunden auf $37^{\circ} \mathrm{C}$. Dem Anscheine nach schwimmt auf der Oberfläche die ganze zugesetzte Menge der Fettsäure noch. Wenige Krystallflitter, die sich gelb gefärbt haben, sind auch im Inneren der Flüssigkeit zu sehen. Am Boden finden sich keine Flitter. Die Senkung unter die Oberfläche erkläre ich mir aus der starken Imbibition mit Farbstoff, der das specifische Gewicht der Krystalle gesteigert hat.

Ich habe ganz genau denselben Versuch mit $0,1 \mathrm{~g}$ Palmitinsäure angestellt, welche ich mit $100 \mathrm{ccm}$ frischer alkalischer Galle 24 Stunden bis $37^{\circ} \mathrm{C}$. erwärmte. leh erhielt genan dasselbe negative Ergebniss wie mit der Stearinsäure.

Wenn Galle die festen Fettsäuren löst, so kann es sich nur um Spuren handeln, die zur Erklärung der Fettresorption nicht von Bedeutung sind.

B. Moore und D. P. Rockwood ${ }^{1}$ geben an, dass die Galle weniger als $0,5 \%$ Palmitin- oder Stearinsäure löse. Ich muss diesen Werth also auf weniger als $1,1 \%$ herabsetzen.

Fs musste demgemïss meine Aufgabe sein, zu prüfen, ob die stets bei der natürlichen Ernährung neben den festen Fettsäuren im Dünndarm gleichzeitig vorhandene Oelsäure zur Lösung der Palmitinsäure und Stearinsäure in der Galle beizutragen vermag.

\section{Versuch 14.}

In einem $200 \mathrm{ccm}-\mathrm{Kölbchen} \mathrm{wurden} 0,040 \mathrm{~g}$ Stearinsäure abgewogen and $5 \mathrm{cem}$ Oelsäure hinzugegeben. Dann wurde erwärmt, bis die Stearinsäure in der Oelsäure sich vollkommen gelöst hatte. Frische, schwach angesäuerte Ochsengalle wurde dann bis in den Hals des Kölbchens eingefült und bei $: 37^{\circ} \mathrm{C}$. erwärmt. Schnell ist Alles gelöst. Allmälig füge ich immer mehr Oelsäure zu und gelange so zu nahezu $10 \mathrm{ccm}$ Oelsäure, die ausser den $0,040 \mathrm{~g}$ Stearinsäure vollkommen gelöst wurden.

1) Proceed. Roy. Soc. Isondon vol. 60 p. 439. 
Das Ergebniss wäre also:

$100 \mathrm{ccm}$ Galle lösten $5 \mathrm{ccm}$ Oelsäure $+0,020 \mathrm{~g}$ Stearinsäure.

Versuch 15 .

Im Kölbchen werden $0,165 \mathrm{~g}$ Stearinsäure abgewogen, $5 \mathrm{ccm}$ Oelsäure hinzugegeben und erwärmt, bis die Stearinsäure sich in der Oelsäure vollkommen gelöst hatte. Es werden $150 \mathrm{ccm}$ frische, schwach mit $\mathrm{ClH}$ angesäuerte Ochsengalle hinzugefügt und geschüttelt. Sehr schnell ist vollkommene Lösung eingetreten, die auch bleibt, als ich 24 Stunden lang auf $37^{\circ}$ C. erwärmte. Ich hatte die Mischung immer in eine geeignete Flasche mit engem Halse gebracht, so zwar, dass die Flüssigkeit bis in den Hals reichte. Ist dann fein vertheiltes Fett da, so steigt es langsam zur Oberiläche, und man erkennt an der hier auftretenden weisslichen Schicht, dass eine vollkommene Lösung nicht stattgefunden hat, während die klare Durchsichtigkeit der im Hals stehenden Flüssigkeit die stattgehabte Lösung bezeugt.

Dieser Versuch ergibt also:

$100 \mathrm{ccm}$ Galle (schwach sauer) lösten $0,110 \mathrm{~g}$ Stearinsäure $+2,7 \mathrm{~g}$ Oelsäure.

Versuch 16.

Abgewogen im $200 \mathrm{ecm}$ Kölbchen $0,515 \mathrm{~g}$ Stearinsäure. Hinzugegeben $10 \mathrm{ccm}$ Oelsäure, erwärmt bis zur vollkommenen Lösung der Stearinsäure, dann mit schwach angesäuerter Galle aufgefüllt und bei $37^{\circ}$ C. 24 Stunden erwärmt. Im Hals des Kölbehens ist eine allerdings kleine Schicht einer sehr feinen Emulsion, obwohl vielmals geschüttelt worden war. Ergebniss:

$100 \mathrm{cem}$ schwach saure Galle haben nicht ganz gelöst $0,257 \mathrm{~g}$ Stearinsäure +5 cem Oelsäure.

\section{Versuch 17 .}

Es werden im $300 \mathrm{ccm}-K o ̈ l b c h e n$ abgewogen $0,5 \mathrm{~g}$ Stearinsäure, $15 \mathrm{ccm}$ Oelsäure hinzugegeben, erwärmt bis zur Lösung der Stearinsäure, aufgefüllt mit schwach angesäuerter Galle bis in den Hals des Kölbchens nnd 24 Stunden auf $37^{\circ} \mathrm{C}$. erwärmt. Es hat keine vollständige Lösung stattgefunden. Denn die oberen Schichten der Mischung enthalten eine allerdings geringe Menge von Emulsion. Demnach : 
$100 \mathrm{ccm}$ Galle lösten nicht ganz $5 \mathrm{ccm}$ Oelsäure $+0,166 \mathrm{~g}$ Stearinsäure.

Das Frgebniss der angeführten Versuche ist also:

Schwach saure Galle löst kleine Mengen von Stearinsäure orler Palmitinsäure allerdings auf, wenn sie vorher durch Oelsäure in Lösung gebracht worden sind.

Weil sich der in den Dünndarm ergossenen alkalischen Galle bei der Verdauung und Resorption des Fettes fortwährend der durch kohlensaures Natron alkalische Bauchspeichel und Darmsaft beimengt, bleibt uns die Aufgabe, die Lösungskraft der mit Sodalösung gemischten Galle für Fettsäuren festzustellen.

\section{Versuch 18.}

50 ccm filtrirte, aber nicht neutralisirte, also alkalische, ganz frische Ochsengalle,

$190 \mathrm{ccm}$ Sodalösung von $1 \%$ (statt $197,5 \mathrm{cem}$ ),

5 g Palmitinsäure,

$5 \mathrm{~g}$ Delsäure.

Um 12 Uhr begonnen mit Frwärmmng auf $37^{\circ} \mathrm{C}$. Un 7 Uhr Abends befindet sich ein ungeheurer Niederschlag am Boden des Kolbens; der Niederschlag nimmt ungeführ die untere Hälfte der ganzen Flüssigkeit ein; er besteht aus Flocken und einem grobkörnigen Pulver und ist schneeweiss. -

Auf der Oberfläche befiudet sich eine mässige Schicht weisser Krümel und Flöckchen. Sonst ist die Flüssigkeit ziemlich klar. --

Am anderen Moroen hat sich die obere Schicht verringert; die untere am Boden ist etwas geschrumpft. Die Flüssigkeit erscheint trüb.

Im grossen 'Trockenschrank wird nun nach mehrmaliger Filtration durch das Papier "Blauband Nr. 589" von Schleicher und Schüll ein klares Filtrat von $50 \mathrm{ccm}$ erhalten, das mit Aether ausgeschüttelt wird und liefert:

$$
0,723 \mathrm{~g} .
$$

Folglich enthält die ganze Mischung:

$$
3,615 \mathrm{~g} \text { rohe Fettsäure, }
$$
$\frac{\text { geht ab } 0,029 \mathrm{~g} \text { präexistirender Aetherextract, }}{3,586 \mathrm{~g} \text { gelöste Fettsäure. }}$ 
100 cem Galle haben also gelöst:

\section{$7,172 \mathrm{~g}$ Fettsäuren.}

Es war nun vom höchsten Interesse, zu prüfen, woraus die mächtigen weissen Niederschläge bestehen, welche sich aus der Gallenmischung abscheiden, nachdem das Gemenge von Oelsäure und Palmitinsäure hinzugefügt worden ist.

Durch besondere Versuche habe ich mich überzeugt, dass gewöhnliche filtrirte alkalische oder schwach saure Galle bei Erwärmung auf $37^{\circ} \mathrm{C}$. in 24 Stunden nur Spuren eines feinen Staubes absetzt. Das ändert sich auch wenig, wenn der Galle, wie bei diesen Versuchen, die entsprechende Sodalösung zugefügt wird. Solange ich mit der Oelsäure arbeitete, habe ich nichts von den gewaltigen Niederschlägen wahrgenommen, die erst nach Anwendung der festen Fettsäure erscheinen.

Hat man der frisehen Galle Soda und das Gemenge von Oelsäure und Palmitinsäure zugefügt, so erhält man beim Umschütteln eine weisse Emulsion, aus der rasch grobe Flocken weisser Krystalle zur Oberfläche steigen, wenn man auch vorher die Oelsäure und Palmitinsäure durch Erwärmen in ein flüssiges Oel verwandelt hatte. Alsbald vollzieht sich ein merkwürdiger Vorgang: denn aus der an der Oberfläche schwimmenden Schicht der fetten Säuren lösen sich Theile los und sinken rasch zu Boden. Bald ist so ein gewaltiger Satz am Boden entstanden. Es ist klar, dass die sinkenden Flocken keine Fettsäuren sein können. Was sie sind, ergibt sich leicht.

Der abfiltrirte und mit Aether woblgewaschene Niederschlag wird vom Filter in eine Flasche gebracht und mit viel Aether tüchtig ausgeschüttelt. Dann wird filtrirt, der Niederschlag vom Filter auf Filtrirpapier gebracht und ausgebreitet. Er schrumpft stark und schnell zu kleineren, schneeweissen, sehr leichten Bröckchen, die sich mit dem Glasstab zu einem Pulver zerdrücken lassen. Bei schärferem Trocknen unter $100^{\circ} \mathrm{C}$. werden die Bröckchen gelblich.

Sie lösen sich in heissem Wasser zu einer schwach opalisirenden Flüssigkeit; ebenso sind sie in Alkohol löslich, nicht in Aether. Versetzt man die wässrige Lösung mit ein wenig Salzsäure oder Schwefelsäure, so scheiden sich reichliche weisse Flocken aus. Schüttelt man diese Mischung mit Aether, so nimmt dieselbe die Flocken auf, während die wässrige Flüssigkeit klar geworden und ihre Opalescenz fast ganz verloren hat. -

Die Substanz der weissen Bröckehen verbrennt auf dem Platinblech und erzeugt einen 'Geruch nach ranzigem Oel. 
Sie hinterlässt dann eine alkalische Asche, die mit verdünnter Salzsäure mächtig aufbraust. --

In Erwägung, dass nach allen bisherigen Versuchen diese Substanz nur aus der Gallenmischung sich abscheidet, wenn ihr Palmitinsäure und Soda zugesetzt worden sind, muss man es für fast sicher halten, dass sie eine Seife der Palmitinsäure ist. -

Zur Bestätigung dieser Schlussfolgerung werden $1,581 \mathrm{~g}$ der getrockneten Substanz in der Platinschale vorsichtig und langsam verascht.

Wäre die Substanz das reine Natronsalz der Palmitinsäure, so müsste sie $0,301 \mathrm{~g}$ Natriumearbonat als Asche liefern. Also

$$
\begin{aligned}
& \text { Berechnet . . . } 0,301 \mathrm{~g} \text { Asche } \\
& \text { Gefunden . . } 0,293 \mathrm{~g} \text { " }
\end{aligned}
$$

Die Asche löste sich leicht in destillirtem Wasser mit Hintelassung einiger Kohlestäubchen. Vorsichtig nach Filtration in der Platinschale abgedampft und geglüht, erhalte ich genau wieder $0,291 \mathrm{~g}$ Asche.

Die abermals in Wasser gelöste Asche reagirt alkalisch, braust mit verdünnter Salzsäure stark auf. Mit $\mathrm{NO}_{3} \mathrm{H}$ und $\mathrm{NO}_{3} \mathrm{Ag}$ ist kaum eine Trübung zu bemerken, ebenso wenig mit $\mathrm{ClH}$ und $\mathrm{Cl}_{2} \mathrm{Ba}$; ebenso fällt die Phosphorsäurc-Reaction canz negativ aus. - Dahingegen ist eben eine Spur Kalk nachzuweisen. - Eine grössere Menge des wässrigen Auszuges wird eingeengt, mit Salzsäure, Spiritus und Platinchlorid auf Kalium geprüft, ohne eine Spur von Reaction.

Die Asche besteht also fast nur aus Natriumcarbonat, und der in der Galle entstandene Niederschlag war Natriumpalmitat. Leider versäumte ich den Schmelzpunkt der aus der Seife abgeschiedenen Palmitinsäure zu bestimmen, habe dies aber bei den Versuchen nachgeholt, die ich mit der Stearinsäure angestellt und bald besclireiben werde.

Der in der Gallenmischung entstandene Niederschlag, der fast nur aus Natriumpalmitat bestand, kann nicht anders erklärt werden, als dass eine kräftige Seifenbildung stattgefunden hat, die schnell zu einer Sättigung der Flüssigkeit mit Natriumpalmitat führte. Denn diese Seife ist sehr wenig in Wasser, etwas besser, aber auch nicht reichlich in Galle löslich. In neuerer Zeit ist diese Thatsache durch eine Untersuchung genauer festgestellt worden, die von Benjam in Moore E. Fofinger, Archiv für Physiologie. Ba. 86. 
und William H. Parker ${ }^{1}$ ) ausgeführt worden ist. Zur besseren Begründung der Thatsache und Bequemlichkeit des Lesers theile ich die werthvolle Tabelle der beiden englischen Forscher mit:

\begin{tabular}{|c|c|c|c|}
\hline \multicolumn{3}{|c|}{ Es lösen sich in 100 Theilen von } & \\
\hline $\begin{array}{l}\text { destillirtem } \\
\text { Wasser }\end{array}$ & $\begin{array}{l}\text { Lösung } \\
\text { von Cholaten }{ }^{2} \text { ) }\end{array}$ & $\begin{array}{c}\text { Lösung } \\
\text { von Cholaten } \\
\left.\text { Lecithin }^{2}\right)\end{array}+$ & \\
\hline weniger als 0,1 & 0,5 & 4,0 & Oelsäure \\
\hline weniger als 0,1 & 0,1 & 0,6 & Palmitinsäure \\
\hline weniger als 0,1 & weniger als 0,1 & 0,2 & Stearinsäure \\
\hline 5,0 & 7,6 & 11,6 & Natriumoleat \\
\hline 0,2 & 1,0 & $\quad 2,4$ & Natriumpalmitat \\
\hline 0,1 & 0,2 & 0,7 & Natriumstearat \\
\hline- & 0,2 & 1,4 & Calciumoleat \\
\hline- & weniger als 0,1 & 0,9 & Calciumpalmitat \\
\hline - & weniger als 0,1 & 0,4 & Calciumstearat \\
\hline 一 & 3,2 & 8,2 & Magnesiumoleat \\
\hline - & 0,2 & 1,2 & Magnesiumpalmitat \\
\hline 一 & weniger als 0,1 & 1,0 & Magnesiumstearat \\
\hline 一 & 7,0 & - & Lecithin \\
\hline- & 0,1 & 0,15 & Cholesterin \\
\hline
\end{tabular}

Diese Tabelle macht sofort klar, wesshalb ich bei der Verseifung der Oelsäure in der Gallenmischung keine Niederschläge beobachtete, und wesshalb sie bei der Verseifung von Palmitinsäure so massenhaft auftreten. Denn die Palmitinsäure und ihr Natronsalz werden von der Oelsäure an Löslichkeit um das Vielfache übertroffen.

Bei dem hier besprochenen Versuche bleibt noch die wichtige Aufgabe zu lösen, wieviel von der angewandten Palmitinsäure durch die Gallenmischung verwerthet worden ist. Wenn ein klares Filtrat zu erhalten war, wie es hier der Fall gewesen ist, dann müssen die freien, ungelösten Fettsäuren auf dem Filter bleiben. Nachdem gut abgetropft war, wurde das ganze Filter in Aether gebracht und ausgeschüttelt. Die Seifen blieben ungelöst. Nachdem das Unlösliche sich gut abgesetzt hatte, wurde die obere Schicht des klaren Aethers in ein $100 \mathrm{ccm}-$ Kölbchen bis zur Marke gefüllt, verdunstet und

1) Proceedings Royal Soc. London vol. 68 p. $64-76$. - Siehe auch Chem. Centralblatt 1901 N. 17 S. 959.

2) Die lösenden Flüssigkeiten enthielten entweder nur $5 \%$ Cholate oder $5 \%$ Cholate $+1 \%$ Lecithin. 
0,7475 g Palmitinsäurekrystalle erhalten. Unter Beachtung des Gesammtvolums des Aethers ergibt sich als unverändert wiedergefundene Fettsäure

\section{2,3780 g.}

Der Werth ist zu unserem Schaden - denn er ist Subtrahend zu gross, weil ja das den Niederschlag tragende nasse Filter noch gelöste Palmitinsäure und Oelsäure enthielt. Sieht man hiervon $a b$, so ergibt sich:

angewandt . . . . . . . . . $10,000 \mathrm{~g}$ Oelsäure und

nicht verwerthet . . . . . . . $2,377 \mathrm{~g}$ Fettsäure,

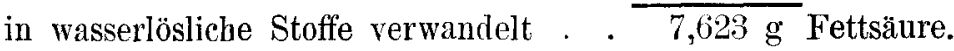

Also, weil dies durch $50 \mathrm{ccm}$ Galle bewirkt war, so folgt:

$100 \mathrm{cem}$ Galle verwerthen . $15,246 \mathrm{~g}$ Fettsäuren.

Nun hatten wir ferner gefunden, dass als freie Fettsäuren, d. h. ummittelbar mit Aether ausschüttelbar, gelöst waren nach dem Verhältniss:

$100 \mathrm{ccm}$ Galle . . $7,172 \mathrm{~g}$ als solche gelöste Fettsäuren, ferner . . . . . $15,246 \mathrm{~g}$ gelöste und verseifte Fettsäuren,

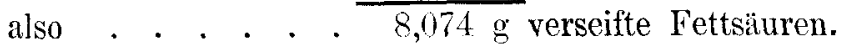

Also $76,2 \%$ der angewandten Fettsäuren sind in wasserlösliche Stoffe verwandelt.

Vergleicht man diesen Versuch mit den früheren, in denen nur Delsäure angewandt wurde, ergibt sich ein ungeheurer Unterschied mit Rücksicht auf die Verseifung. Denn während von der Oelsäure nur ein kleiner Bruchtheil verseift wurde, ist jetzt die verseifte Menge der Fettsäuren grösser als die gelöste.

Die in plysiologischer Beziehung wichtigste Erscheinung besteht aber in der ansserordentlich mächtigen Wirkung, welche die Galle bei Gegenwart von Soda auf die Palmitinsäure ausübte, indem sie daraus wasserlösliche Stoffe erzeugte. Ich werde auf diesen bedeutsamen punkt später nochmals zurückkommen.

\section{Versuch 19.}

Der jetzt $\mathrm{zu}$ beschreibende Versuch ist eine Wiederholung des vorigen Versuches 18, mit dem einzigen Unterschied, dass statt der Sodalösung ein gleiches Volum Wasser angewandt wurde. Versuch 18 und Versuch 19 sind an demselben Tag mit derselben Galle angestellt. Also: 
50 cem Galle,

$190 \mathrm{cem}$ Wasser,

5 g Palmitinsäure,

5 g Oelsäure.

Die Mischung wird 19 Stunden bei $37^{\circ}$ C. erwärmt. Trotz wiederholten Umschüttelns bildet sich diesmal kein Niederschlag am Boden aus. Damit ist auch bewiesen, dass die zugesetzte Soda bei der Bildung des Niederschlages betheiligt ist. Da wir durch den vorigen Versuch 18 wissen, dass der Niedersehlag die Natronseife der Palmitinsäure ist, versteht sich dlas Ergebniss dieses Versuches 19 leicht. Die in der Galle selbst enthaltenen Natronsalze, welche wenigstens zum Theil auch zur Seifenbildung herangezogen werden, sind also nicht in hinreichender Menge vorhanden, um eine Uebersättigung der Flüssigkeit mit Seife hervorzubringen.

Bei dieser Mischung fand sich also kein Bodensatz, wohl aber eine ungefähr $1 \mathrm{~cm}$ hohe, weisse Schicht auf der Oberfläche der Flüssigkeit. Darunter erschien eine weisslich-grünliche Emulsion.

Nach 19 Stunden wird bei $40^{\circ}$ C. durch ein Schnellfilter gegossen. Das Filtrat ist klar, durchsichtig und fast ohne Opalescenz.

$50 \mathrm{cem}$ des Filtrates werden mit Aether ausgeschüttelt und liefern $0,196 \mathrm{~g}$ Aetherextract; folglich beträgt der Gesammtwerth der gelösten rohen Fettsäuren . . . . . . . . 0,9800 g hiervon ab der präformirte Aetherextract . • • . • $\frac{0,0293 \text { ” }}{0,9509 \mathrm{~g}}$
Also gelöste Fettsäuren . . . . . . . . . $100 \mathrm{ccm}$ Galle würden gelöst haben nur $1,9014 \mathrm{~g}$.

Die auf dem Filter befindlichen ungelösten Massen werden nun mit Aether ausgeschüttelt. Es wurden erhalten 9,29019 g Aetherextract. Der Werth muss ein wenig zu gross sein, weil die auf dem Filter befindlichen ungelösten Massen noch mit ein wenig gelöster Fettsäure verunreinigt waren. Es ergibt sich demnach:

Wiedergefunden ungelöste Fettsäuren. . . . $9,2902 \mathrm{~g}$

Summe . . . . . . . . . . . . . . . . . . . . $\frac{0,9507 \text { n }}{10,2409 \mathrm{~g}}$

Da nur $10 \mathrm{~g}$ Fettsäuren angewandt wurden, sind aus oben angegebenem Grunde zu viel gefunden 0,2408 g Fettsäure. Wenn eine Verseifung stattgefunden hat, so liegt sie in den unvermeidlichen Beobachtungsfehlern verborgen.

Die Abwesenheit der Soda hat also eine bedeutende Störung der Arbeit der Galle bedingt. 
Denn während bei dem vorigen Versuch 19 (Anwesenheit von Soda) von den angewandten Fettsäuren $35,9 \%$ als solche gelöst wurden, ist diesmal dieser Werth auf $9,5 \%$ gesunken.

Während bei dem vơrigen Versuch $19 \quad 40,4 \%$ der Fettsäuren verseift wurden, ist diesmal die Verseifung nicht mit Sicherheit zu beweisen.

\section{Versuch 20.}

Nunmehr soll der Versuch 19 wiederholt werden, mit der Abänderung, dass statt Palmitinsäure in Anwendung kommt ein gleiches Gewicht Stearinsäure. Die zu dem Versuche 20 gebrauchte Galle ist dieselbe, welche zu Versuch 18 und 19 benutzt wurde.

$\left.\begin{array}{l}5 \mathrm{~g} \text { Stearinsäure } \\ 5 \mathrm{~g} \text { Oleïnsäure }\end{array}\right\}$ im Kölbchen seschmolzen.

$\mathrm{Zu}$ dem entstandenen Oel wird gegossen:

$50 \mathrm{ccm}$ Galle (alkalisch), $190 \mathrm{ccm}$ Sodalösung von $1 \%$.

Die entstandene Emulsion wird 19 Stunden auf $37^{\circ} \mathrm{C}$. erwärmt.

Geradeso wie bei Versuch 18 mit Palmitinsäure hat sich eine obere Schicht, die aus weissen Flocken besteht, gebildct, sowie ein am Boden befindlicher mächtiger schneoweisser Satz. Im grossen Trockensehrank werden bei $40^{\circ} \mathrm{C} .50 \mathrm{ccm}$ klar abfiltrirt, um nit Aether ausgeschüttelt zu werden. Dann wurden $30 \mathrm{ccm}$ desselben klaren Filtrates mit Salzsäure angesäuert und ebenfalls mit Aether ungeschüttelt. Die Differenz der so erhaltenen Werthe musste ergeben, wieviel Fettsäure als solche und wieviel als Seife gelöst war.

Die angesäuerte Probe (30 ccm) ergab $0,723 \mathrm{~g}$ Aetherextract Folglich enthielt die ganze Mischung (250 ccm) 6,025 " " ab praeformirt in $50 \mathrm{~cm}$ angesäuerte Galle $0,069 "$ ",

Die nicht angesüuerten 50 cem Filtrat liefern: $0,933 \mathrm{~g}$ Aetherextract.

In der gesammten Mischung von $250 \mathrm{ccm}$ sind also enthalten: gelöst . . . . . . . . . . 4,665 Aetherextract ab hiervon der in der alkalisehen Galle praeformirte Aetherextract $\frac{.0,029 \quad \#}{4,636 \text { Fettsüuren (gelöste). }}$ 
Also :

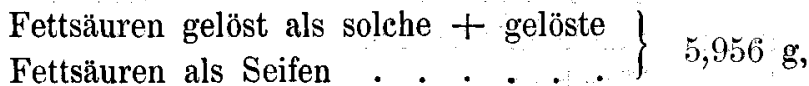

Fettsäuren als solche gelöst $\therefore \quad . \quad$. 4,636

Fettsäure in Seifen . . • . . . . 1,320 g.

Folglich würden $100 \mathrm{ccm}$ Galle + Soda lösen:

2,640 Fettsäuren in Seifen.

$\mathrm{Es}$ ist aber von Interesse, noch zu wisser, wie gross der gesammte Retrag der gebildeten Seife ist. Die auf dem Filter gebliebenen ungelösten Massen werden mit Aether ausgeschüttelt. Es werden erhalten $2,706 \mathrm{~g}$ Fettsäuren. Der Werth ist aus bereits angegebenen Gründen ein wenig zu gross.

Gesammtmenge der angewandten Fettsäuren . . . 10,000 g

Nicht verwerthete Fettsäuren (weder gelöst noch verseift) 2,706 "

In wasserlösliche Form übergeführte Fettsäuren . . . 7,294 g

Da dies durch $50 \mathrm{ccm}$ Galle + Soda erzielt wurde, ergiebt sich, dass $100 \mathrm{ccm}$ Galle in wasserlösliche Form überführen:

$14,588 \mathrm{~g}$ Fettsäuren.

Dieser Werth ist innerhalb der Fehlergrenzen derselbe, den wir in Versuch 18 erhielten, wo statt der Stearinsäure die Palmitinsäure in Anwendung kam.

Weil bei diesem Versuche die gelösten und nicht gelösten Seifen gesondert bestimmt wurden, ergibt sich noch folgende Uebersicht: $100 \mathrm{ccm}$ Galle + Soda haben gelöst als solche . 9,272 g Fettsäuren

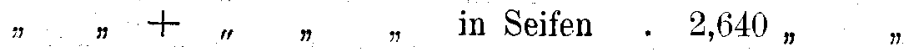

$" \quad+\quad$ liefern in ungelösten Seifen $2,676 "$

Durch Galle + Soda verarbeitet: Summa 14,588 $\mathrm{g}$ Fettsäuren.

Ich wünsche endlich bei diesem Versuche, den strengeren Beweis zu erbringen, dass die während der Erwärmung der Gallenmischung auftretenden mächtigen Niederschläge nichts weiter sind als Natriumstearat.

Die abfiltrirte, mit Aether erschöpfte, getrocknete, schneeweisse, wegen Durchlässigkeit des Filters nicht vollständig erhaltene Seifenmasse wog:

$$
2,0113 \cdot \mathrm{g} \text {. }
$$

Hiervon $0,876 \mathrm{~g}$ in der Platinschale verascht liefern:

Asche . . . 0,1545 gefunden,

Asche . . 0,1517 berechnet.

Die Uebereinstimmung in Beobachtung und Rechnung ist befriedigend. 
Die Asche wird mit Wasser ausgezogen, filtrirt, nochmals verdunstet und geglüht. Wieder erhalten:

$0,1538 \mathrm{~g}$ Wasserextract der Asche.

Also ist fast die ganze Asche in Wasser löslich.

Auf dem Filter war eine Spur grauen Staubes geblieben. Ich giesse verdünnte Salzsäure auf das Filter. Das Filtrat gibt eine Spur von Kalkreaction, die aber unzweifelhaft ist. -

Der Wasserauszug der Asche braust mit verdünnter Salzsäure mächtig auf, gibt keine Reaction auf Kali, Kalk, Magnesia, Chlor, Schwefelsäure, Phosphorsäure.

Die Asche ist also sicher fast reines Natriumcarbonat mit einer Spur von Kalk. -

Ich nehme nun $1,1353 g$ derselben Seife, löse sie in heissem Wasser im Kölbchen, zersetze mit Salzsäure und sehe, dass sich reichliche weisse Flocken ausscheiden, die offenbar Stearinsäure sind. Ich schuttele mit Aether aus, erhalte nach Verdunsten weisse, perlmutterglänzende Krystalle. Ich bestimme den Schmelzpunkt und finde, dass die Substanz bei $68^{\circ} \mathrm{C}$. zu schmelzen anfängt und bei $70,5^{\circ}$ C. ganz durehsichtig und flüssig geworden ist. Es ist also sicher, dass der in der Gallenmischung nach Zusatz fester Fettsäuren und Soda entstehende Niederschlag aus den Natronseifen dieser Fettsäuren besteht.

\section{Versuch 21 .}

Auch zur Ergänzung von Versuch 20 wiederholte ich die bei demselben befolgte Anordnung mit der Abänderung, dass statt $190 \mathrm{ccm}$ Sodalösung nur $190 \mathrm{cem}$ Wasser in Anwendung gezogen wurden. Also:

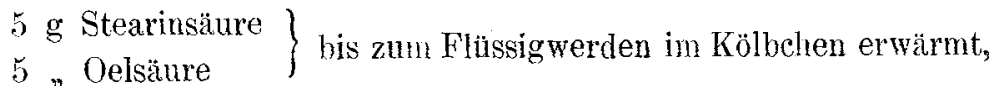

50 cem Galle (dieselhe wie bisher),

190, Wasser

14 Stunden erwärmt bei $37^{\circ} \mathrm{C}$.

Oben schwimmt die Schicht weisser Flocken; kein Bodensatz hat sich gebildet.

Filtration bei $40^{\circ} \mathrm{C}$. liefert ein klares Filtrat.

50 cem Filtrat geben - . 0,189 g Aetherextract

Im Ganzen also . . . . 0,9450),

ab präformirter Extract . 0,0293 , 
Der Aetherauszug der auf dem Filter befindlichen ungelösten Massen liefert (etwas zu gross):

$9,4488 \mathrm{~g}$ ungelöste Fettsäure, 0,9157 „gelöste Fettsäure,

$10,3645 \mathrm{~g}$ wieder gefunden.

Abermals ist die Seifenbildung so gering, dass sie dureh die Beobachtungsfehler verdeckt wird.

\section{Versuch 22.}

Es war noch wünschenswerth, einen Einblick zu gewinnen in die Bedeutung, welche der Galle und Oelsäure bei der Verseifung der Palmitinsäure und Stearinsäure zukommt. Ich machte desshalb mit derselben frischen, alkalischen, filtrirten Ochsengalle gleichzeitig folgende vier Versuche:

I.

$5 \mathrm{~g}$ Stearinsäure,

$0,0 \mathrm{~g}$ Oelsäure,

$190 \mathrm{cem}$ Sodalösung von $1 \%$ $50 \mathrm{ccm}$ Wasser.

III.

$5 \mathrm{~g}$ Stearinsäure, $0,0 \mathrm{~g}$ Oelsäure,

$190 \mathrm{cem}$ Sodalösung von $1 \%$, $50 \mathrm{cem}$ Galle.
II.

5 g Stearinsäture, $5 \mathrm{~g}$ Oelsäure, $190 \mathrm{ccm}$ Sodalösung von $1 \%$, 50 cem Wasser.

IV.

$5 \mathrm{~g}$ Stearinsäure, $5 \mathrm{~g}$ Oelsäure, $190 \mathrm{cem}$ Sodalösung von $1 \%$, $50 \mathrm{ccm}$ Galle.

Jede Mischung befand sich in einem $300 \mathrm{ccm}-\mathrm{Kölbchen.} \mathrm{Alle}$ 4 Kölbchen waren wohl zugestöpselt in ein Bad von $38^{\circ} \mathrm{C}$. eingesenkt. Schon nach einer Stunde war ein sehr grosser Unterschied vorhanden, der fortwährend zunahm und Folgendes ergab:

In Flasche IV hatte sich nach 7 Stunden ein ungeheurer, dichter Niederschlag von weisser Farbe gebildet, der ungefähr $1 / 4$ des Volums der ganzen Flüssigkeit am Boden der Gefässes ausmachte. Ias Gesammtvolum betrug ja annähernd $250 \mathrm{ccm}$.

In der obersten Schicht der Flüssigkeit befand sich eine aus vielen weissen Flocken und Klümpchen bestehende Schicht, die unzweifelhaft wesentlich aus Fettsäure bestand. Zwischen der oberen weissen und der unteren weissen Schicht zeigte sich die durch die Galle grünlich gefärbte, schwach getrübte Flüssigkeit, in der einige wenige weisse Flöckchen und Klümpchen schwammen. 
Da ich bewiesen habe, dass die untere Schicht aus Natriumstearat besteht, so folgt, dass eine sehr kräftige Verseifung der Stearinsäure stattgefunden hatte.

In Folge des Vorschreitens dieses Vorganges nahm die oben schwimmende Schicht an Fettsäuren fortwährend $a b$, die untere entsprechend $\mathrm{zu}$. Nach $2 \times 24$ Stunden schwammen oben nur noch ein paar Flöckchen, die sicher noch nicht $0,1 \mathrm{~g}$ wogen.

Nach $4 \times 24$ Stunden war keine Spur eines Flöckchens mehr in der ganz klaren, schwach gelblichen Flüssigkeit zu sehen. Der ungeheure weisse Niederschlag am Boden nahm ungefähr ${ }^{1 / 3}$ des Volums der Flüssigkeit ein. Dieser Niederschlag ist äusserst leicht aufrüttelbar und besteht aus einem unendlich feinen Staub, der durch die meisten Filter geht und sie allmälig immer undurchlässiger macht, wesshalb es schwer ist, denselben ohne Verlust abzufiltriren. Ich habe oben strenge bewiesen, dass der mit Aether gewaschene Niederschlag

\section{Natriumstearat}

ist.

Dabei ist allerdings zu bedenken, dass ich den Niederschlag immer erst untersuchte, nachdem ich ihn durch Waschen mit Aether von anhängenden Fettsäuren befreit hatte. Demnach bleibt die Frage offen, ob bei der Verseifung der ungelösten Fettsüuren eine Substanz entsteht, die melır oder weniger noch nicht verseifte Fettsäuren mechanisch einschliesst. Da bei dem hier beschriebenen Versuche der Schein dafür sprach, dass alle ungelösten Fettsäuren in Seifen übergeführt seien, filtrirte ich den mächtigen Niedersehlag ab, presste ab und bestimmte, ob er grössere Mengen Stearinsäure an Aethcr abgeben würde. Dies war der Fall, und die Menge der anspezogenen Stearinsäure war so gross, dass sie unmöglich von der geringen Flüssigkeitsmenge abgeleitet werden konnte, die sich noch in dem ausgepressten Seifenbrei befinden mochte.

Wenden wir uns zu Flasche III, welche nach 7 Stunden noch keine Spur eines weissen Niederschlages darbot, also zu einer Zeit, wo der gewaltige Niedersehlag in der Flasche IV bereits ausgebildet war. Fragt man nach der Ursache der so grossen Verschiedenheit, so ergibt sich, dass die zwei Mischungen sich nur dadurch unterscheiden, dass in Flasche III die Oelsäure fehlte, welche in Flasche IV vorhanden war.

Im Laufe von 24 Stunden erschien aber auch in III eine untere 
Seifenschicht; sie blieb immer viel geringer als die auf der Oberfläche noch massenhaft vorhandene Schicht der Fettsäuren. Selbst als nach mehreren Tagen alle Fettsäuren in IV von der Oberfläche verschwunden waren, übertraf an Massenhaftigkeit die in III befindliche obere Schicht der Fettsäuren die am Boden lagernde der Seifen bei Weitem.

Die Versuche 3 und 4 beweisen, dass die Verseifung der Stearinsäure nnd Palmitinsäure durch Galle in ganz ausserordentlicher Weise gefördert wird, wenn neben den festen Fettsäuren auch Oelsäure vorhanden ist.

Verstänlich wird diese Thatsache, wenn man erwägt, dass nach meinen oben mitgetheilten Ermittlungen die Lösung der Stearinsäure und Palmitinsäure in Galle durch die Gegenwart von Oelsäure erheblich gesteigert wird.

Der bedeutende Widerstand, den die Oelsäure der Verseifung durch Galle entgegensetzt und welcher mich im Anfange so sehr in Erstaunen setzte, erhält jetzt eine tiefe Bedeutung. Denn die freie Oelsäure ist nöthig, um die festen Fettsäuren der Verseifung zugänglich zu machen.

Vergleichen wir nunmehr das Ergebniss von Flasche I und II. Sie unterscheiden sich von III und IV nur dadurch, dass die Galle fehlt, welche durch ein gleiches Volum Wasser ersetzt wurde. Der Unterschied von I und II gegen III und IV besteht zuerst darin, dass selbst nach Verlauf von 24 Stunden kein Bodensatz vorhanden ist. Das beweist, dass ohne Galle die Verseifung der Stearinsäure entweder fehlt oder doch in auffallend geringerem Grade sich geltend machen konnte.

Vergleiche man hierauf I und II unter einander: sie unterscheiden sich dadurch, dass in I die Oelsäure. fehlt, welche in II vorhanden ist. In I schwimmt die Stearinsäure in dichter Schicht auf der Oberfläche, und unter ibr ist eine ganz durchsichtige, kaum getrübte Flüssigkeit, in der keine Flocken zu sehen sind. Da nach M o o re und R ockw o od die Löslichkeit der Natronsalze der. Stearinsäure in Wasser so ausserordentlich klein ist und nur $0,1 \%$ beträgt; so müsste ein Niederschlag am Boden der Flasche I bemerkbar geworden sein, wenn eine irgend erhebliche Verseifung stattgefunden 
hätte. Es war aber nicht einmal ein Anzeichen von Verseifung vorhanden, das sich durch Senkung einiger Flocken der Stearinsäure kundgegeben haben würde. Ich machte die Versuche immer so, dass ich erst die Stearinsäure in das Kölbchen brachte, dann über der Flamme erwärmte, bis ich ein flüssiges Oel erhielt, zu dem ich dann die kalte Sodalösung goss und so lange schüttelte, bis die an der Wand klebende Stearinsäure sich wieder losgelöst und als Flocken in der Flüssigkeit vertheilt hatte.

(Es ist aber nothwendig, zu bemerken, dass ein ganz anderes Ergebniss zu Tage tritt, wenn man zu der geschmolzenen Stearinsäure die äquivalente Sodalösung giesst, nachdem man letztere auch auf cirea $90^{\circ} \mathrm{C}$. erhitzt hat. Schnell gesteht beim Erkalten die Flüssigkeit zu einem steifen Seifenleim.)

Der Inhalt von Flasche II ist stark milchig getrübt und überall von zahlreichen Klumpehen und Flocken durchsetzt, die sich allerdings in um so grösserer Menge vorfinden, je oberflächlicher die Flüssigkeitsschicht ist. Auf dem Boden befinden sich aber nach 24 Stunden auch einige wenige Klümpchen und Flocken.

Da Fettsäuren wie Stearinsäure oder Oelsäure immer, wenn sie in Wasser aufgeschwemmt werden, eine obere Schicht bilden, genau wie es in Flasche I der Fall war, so muss man annehmen, dass das Sinken der Fettsäureflocken nach abwärts dadureh bedingt ist, dass doch eine theilweise Verseifung der Flocken stattgefunden, welche ihr speeifisches Gewicht erhöht hat. Wir gelangen also zu der Erkenntniss, dass auch ohne Galle die Verseifung von Stearinsäure durch die Gegenwart von Oelsäure gefördert wird.

Dass dem so sei, ergab sich nun dadurch, dass allmälig auf dem Boden von II ein weisser Niederschlag sich absetzte und fortwährend wuchs, während die auf der Oberfläche und dicht darunter schwimmenden Fettsäuren immer mehr abnahmen. Nach fünf Tagen war der Vorgang so weit vorgeschritten, dass die Verseifung nahezu vollendet schien; denn die schwimmenden Flocken waren fast ganz verschwunden, und an ihrer Stelle fand sich ein mächtiger Niederschlag am Boden. Es ist also dasselbe Ergebniss in II erreicht worden wie in IV. Nur vollzog sich die Verseifung in IV, d. h. bei Gegenwart von Galle, mehr als doppelt so schnell.

In Flasche I war nach fünf und sechs Tagen die erste. Spur einer Verseifung zu beobachten.

Die Versuche in Flasche I und II beweisen, dass 
Stearinsäure in verdünnter Sodalösung bei $37^{\circ} \mathrm{C}$. bei Gegenwart von Oelsäure viel kräftiger und schneller als ohne diese verseift wird.

\section{§ 4. Ueber die Unlöslichkeit des Neutralfettes in Galle.}

\section{Versuch 23.}

Nachdem ich die mächtig lösende Wirkung gefunden hatte, welche die Galle bei Gegenwart von Soda auf die Fettsäuren ausübt, musste ich daran denken, dass Fettsäuren neutrale Fette zu lösen vermögen. Da nun viel Fettsäure bei den gedachten Versuchen in der Gallenmischung sich in Lösung befindet, so sollte man meinen, dass dieselbe auch neutrale Fette in Lösung überzuführen vermöchte. Gilt doch ganz Aehnliches für die Stearinsäure und Palmitinsäure, welche, an sich in Galle fast unlöslich, sofort, wenn auch nicht reichlich, in Lösung gehen, wenn Oelsäure gleichzeitig gelöst ist.

In ein Kölbchen wurden gebracht:

$10 \mathrm{~g}$ Oelsäure,

1 ccm Olivenöl, $190 \mathrm{cem}$ Sodalösung von $1 \%$.

Es ist eine weisse Emulsion mit vielen weissen Flocken entstanden.

Nachdem $100 \mathrm{ccm}$ Galle hinzugefügt waren, verschwindet beim Schütteln die Emulsion schnell fast ganz. Darauf bei $37^{\circ} \mathrm{C}$. über Nacht erwärmt. Es ist eine obere Schicht einer feinsten Emulsion vorhanden, die bei wiederholtem Schütteln immer wierer erscheint.

Ich setze desshalb nochmals $100 \mathrm{ccm}$ Galle zu, so dass jetzt bei Gegenwart von Soda auf $10 \mathrm{~g}$ Oelsäure $200 \mathrm{ccm}$ Galle kommen, die mehr als ausreichen. um die Oelsäure zu lösen. Bei abermaliger Erwärmung der Mischung auf $37^{\circ} \mathrm{C}$. erseheint aber doch wieder eine obere Schicht, in der sich eine Fettemulsion befindet, die sich durch grössere Fetttröpfchen auszeichnet.

Wenn dieser Versuch auch nicht ausschliesst, dass unter diesen Verhältnissen Neutralfett in Lösung ging, so ist dessen Menge doch eine so kleine, dass sie für die Erklärung der Fettresorption keine wesentliche Bedeutung beanspruchen könnte. 


\section{§ 5. Ueber die Zustände in Wasser gelöster Seifen.}

Die beutige Lehre, welche sich wesentlich noch auf Chevreuil stützt, stellt den Satz auf, dass in Wasser gelöste neutrale Seife durch Zusatz von viel Wasser zersetzt werde - unter Abscheidung der sauren Salze der Fettsäure. Das Verständniss dieses Vorganges ist von Wichtigkeit für die Erklärung der physiologischen Fettresorption.

Ein sehr ähnliches Verhalten zeigen wässrige Lösungen von Mercurinitrat, welche ebenfalls durch Wasserzusatz zersetzt werden - unter Abscheidung basischer Salze. Die Erklärung dieses Vorganges, die ich schon vor langer Zeit ${ }^{1}$ ) gegeben habe, kann nicht zweifelhaft sein. Denn wenn man eine klare Lösung von salpetersaurem Quecksilberoxyd in einer wohlverschlossenen Flasche aufbewahrt, so hält sie sich beliebig lange, und keine Niederschläge setzen sich ab. - Lässt man aber die Flasche geöffnet stehen, so entweicht fortwährend Salpetersäure, und es setzt sich allmälig ein gelbweisser Niederschlag von scbwer löslichem hasischem Salz ab. Hiermit ist bewiesen, dass das Neutralsalz sich auch ohne Wasserzusatz zersetzt, weil es fortwährend Salpetersäure verliert. In der Lösung muss also immer ein kleiner Betrag freier Salpetersäure sein. Da nun diese Abscheidung nicht stattfindet, wenn die Flasche verschlossen bleibt, also die Lösung keine Salpetersäure durch Abdunstung verlieren kann, so ist es klar, dass in diesem Falle Dissociation und Resociation gleich gross sind.

Sobalf ich zu der klaren Lösung des Neutralsalzes Wasser giesse, muss der Procentgehalt der Lösung an freier Salpetersäure abnehmen. Fs ist aber ein bestimmter l'rocentgehalt der freien Süure nöthig, damit hinreichend schnell die durch Dissociation bedingten Verluste der Moleküle wieder ausgeglichen werden könuen. Wo aus dem Neutralsalz ein Molekul Salpetersäure austritt, muss sofort ein anderes Molekül Salpetersäure den frei gewordenen Platz wieder einnehmen, so dass zur Entstehung von basischem Salz keine Zeit bleibt. Das ist nur möglich, wenn in der Lösung des Neutralsalzes etwas mehr Salpetersäure ist, als zur Bildung von Neutralsalz streng gefordert wird.

Der basisches Salz fällende Wasserzusatz beruht also nicht auf einer durch das Wasser bedingten Zersetzung des Neutralsalzes, sondern

1) Dieses Archiv Bd. 21 S. 280.1880. 
vielmehr in einer Beeinträchtigung der Resociation des auch ohne Wasserzusatz sich fortwährend zersetzenden Salzes.

Ich legte mir die Frage vor, ob die Fällung der Seifenlösungen durch viel Wasser auf ähnliche Ursachen zurückgeführt werden müsse.

Versueh 24.

Stearinsäure (Kahlbau m) vom Schmelzpunkt $69^{\circ} \mathrm{C}$. wurde mit alkoholischer Kalilauge heiss verseift. Nach Verjagung des Alkohols löste ich in Wasser und fällte mit einer gesättigten Lösung von chemisch reinem Chlornatrium. Letzteres war auf folgendem Wege von mir dargestellt:

Eine gesättigte Lösung von käuflichem Kochsalz wurde filtrirt, mit Chlorwasserstoff gefällt, durch einen mit Glaswolle verstopften Trichter filtrirt; mit concentrirter Salzsäure gewaschen. Den Krystallbrei brachte ich in eine Porzellanschale, die auf einem Sandbad so lange erhitzt wurde, bis alle Salzsäure ausgetrieben war.

Um die durch das Aussalzen gewonnene Seife vom Kochsalz zu befreien, löste ich in siedendem Alkohol, der das Salz fast ungelöst lässt, filtrirte heiss und liess erkalten. Aus dem Filtrat schied sich die Seife ab. Nachdem dieses Verfahren drei Mal, zuletzt mit grossen Mengen absoluten Alkohols, wiederholt worden war, erwies sich das erhaltene Natriumstearat frei von Chlornatrium. - Denn die wässrige Lösung der Seife schied nach Hinzufügung von ein wenig Schwefelsäure weisse Flocken $a b$, von denen eine klare Flüssigkeit abfiltrirt wurde, die mit salpetersaurem Silber keine Trübung gab.

Die Seife wurde im Trockenschrank bis zu constantem Gewicht getrocknet. Ungefähr $1,1 \mathrm{~g}$ löste ich im Jenaer Kolben in $50 \mathrm{ccm}$ vorher ausgekochtem Wasser, fullte auf $200 \mathrm{ccm}$ Wasser auf, goss in ein grosses Becherglas und fügte allmälig immer neues Wasser hinzu, bis der entstandene Niederschlag nicht mehr zuzunehmen schien. Alles gebrauchte destillirte Wasser hatte ich in Kolben von Jenaer Glas durch längeres heftiges Kochen von seiner Kohlensäure befreit. Auf diese Weise waren schliesslich $3200 \mathrm{ccm}$ Wasser in Anwendung gekommen. Der Niederschlag senkte sich in Wolken; doch sank er nicht ganz zu Boden. Auch wurde die Flüssigkeit in den oberen Schichten selbst nach einem Tage nicht klar, wenn auch hier weniger feiner weisser Staub schwamm.

Auffallend war nur, dass alsbald die freie Oberfläche mit einer Haut überzogen schien, in der grössere Flocken schwammen. Als 
ich einige solche Flocken mit dem Glasstabe herausfischte und in ein Reagensglas brachte, um dann Aether darauf zu giessen, lösten sie sich sofort, und alle vorher vorhandene Trübung war verschwunden. Diese Flocken waren also keine Seife, sondern höchst wahrscheinlich Stearinsäure.

Ich filtrirte nun den erhaltenen Niederschlag ab, was sich schnell und leicht vollzog. Das Filtrat hatte in sehr dicker Schicht eine nur sehr geringe Opalescenz, hinterliess aber beim Verdunsten einen Rückstand, der an Aether nicht die Spur abgab, wohl aber an Alkohol bei wiederholtem Ausziehen $0,030 \mathrm{~g}$. Es hinterblieb noch in der Schale ein geringer Rückstand, den ich als in Wasser fast unlöslich abkratzte. Er wog $0,119 \mathrm{~g}$.

Das Filter mit dem Niederschlag breitete ich, nachdem es gut abgetropft war, auf einem Bausch Filtrirpapier aus und liess es frei an der Luft über Nacht trocknen. Morgens war die schneeweisse etwas glänzende Masse dem Papier fest angetrocknet, löste sich aber überall, wenn ich das Papier bog, fast quantitativ in dünnen Blättern von demselben $a b$. Da diese Blättchen nicht pulverisirbar waren, brachte ich sie in ein tarirtes Wägegläschen und trocknete bis zu constantem Gewicht. Ich erhielt:

\section{$0,9113 \mathrm{~g}$ Substanz.}

Ohne die Substanz aus dem durch einen eingeschliffenen Stöpsel verschliessbaren Wägegläschen herauszunehunen, übergoss ich dieselbe mit kaltem wasserfreiem Aether, zerrieb mit einem Glasstab in diesem den Niederschlag, wiederholte dies, liess mehrere Stunden stehen, filtrirte den Aether durch ein kleines Filterchen ab und liess ohne Erwärmung verdunsten. Es hinterblieb eine auffallend beträchtliche Menge krystallinischer Substanz, die ich zur Reinigung von Seife nochmals mit Aether auszog. Der getroeknete Aetherextract war krystalliniseh, unlöslich in Wasser, löslich in Alkohol und besonders leicht in Aether. Auf dem Platinblech verbrannte ich $100 \mathrm{mg}$ der Substanz, die auch nicht die Spur eines Rückstandes hinterliess. Es konnte also kein Zweifel sein, dass Stearinsäure vorlag. Zur Bestätigung bestimmte ich noch den Schmelzpunkt, den ich zu $69^{\circ} \mathrm{C}$. fand, also genau so wie die angewandte Stearinsäure. Diese Stearinsäure enthält wohl noch eine Spur Palmitinsäure, die den Schmelzpunkt ein wenig herabgedrückt hat. Macht man nun die Annahme, dass das saure Salz aus einem Molekül Neutralsalz und einem Molekül Stearinsäure besteht, und dass 
dieses letztere Molekül durch Aether ausziehbar ist, so müssten $0,911 \mathrm{~g}$ des sauren Natriumstearats liefern:

$$
0,375 \mathrm{~g} \text { Stearinsäure. }
$$

Ich bätte die Substanz gern mit Aether erschöpft; sehr bald lieferte aber jeder Auszug ziemlich gleich viel Extract, der etwa $4-6 \mathrm{mg}$ wog. Nachdem ich im Laufe von mehreren Tagen mehr als 20 Auszüge gemacht hatte, war die Ausbeute schliesslich gewachsen auf: $\quad 0,211 \mathrm{~g}$ Stearinsäure.

Ich verzichtete desshalb auf Fortsetzung des Ausschüttelns und untersuchte zur Ergänzung die mit Aether so lange behandelte Seife auf ihren Gehalt an Natron.

Die bis zu constantem Gewicht getrocknete Seife

$$
0,435 \mathrm{~g}
$$

lieferte beim Verbrennen $0,070 \mathrm{~g}$ Asche, $\mathrm{d}$. h. Soda, welche entsprechen 0,405 g Neutralsalz.

Folglich enthielt die Masse von $0,435 \mathrm{~g}$ Seife noch $0,030 \mathrm{~g}$ Stearinsäure oder $6,9 \%$,

die ursprünglich mit Aether ausgezogene Seife von $0,911 \mathrm{~g}$ enthielt also noch . . . . . . . $0,0629 \mathrm{~g}$ Stearinsäure, ausgezogen mit Aether . . . . · · · $\frac{0,211 \mathrm{~g}}{0,2739 \mathrm{~g}}$ "

während das saure Salz verlangt. . . 0,375 g

Diese Thatsachen sind schwer in Einklang mit der herrsehenden Lehre zu bringen, dass neutrale Seifen durch grössere Wassermengen unter Fällung saurer Salze zersetzt werden.

Unrichtig ist diese Angabe schon desshalb, weil auf der Oberfäche freie Fettsäuren schwimmen. Unwahrscheinlich, dass die sich senkenden Ausscheidungeu ein reines fettsaures Salz seien, weil demselben durch kalten Aether die Fettsäure entzogen werden kann, welche in kleinerer Menge vorhanden ist, als dem Neutralsalz entsprechen würde ${ }^{1}$ ). Dass kalter Aether sogar bei Abwesenheit von

1) Die in meiner Analyse fehlende Stearinsäure erklärt sich daraus, dass die durch das Wasser erzeugte Fällung kein einheitlicher Körper ist, sondern ein Gemenge von Stearinsäureflocken und "saurem Salz". Die Flocken und Häute schwimmen in den oberen Schichten der Flüssigkeit oder überwiegen das saure Salz, während in den unteren Schichten das umgekehrte Verhältniss vorhanden ist. In Folge dessen ist der Ueberzug des grossen Filters - es handelte sich um Filtration von mehr als drei Litern - nicht überall von demselben Stoff gebildet, und nach der Trocknung löste sich nicht überall dieselbe Substanz $a b$, die vollständig natürlich so nicht zu erhalten war. 
Wasser das saure Salz zersetzen sollte, ist doch recht schwer zu denken. Finfacher ist wohl die Annahme, dass in Folge der Verdünnung der Lösung einer neutralen Seife mit Wasser Fettsäure sich abscheidet und Neutralsalz einschliesst. Hiernach wäre das saure Salz nur ein Gemenge von Neutralsalz mit Fettsäure.

Sei dem, wie ihm wolle: für uns liegt die bedeutungsvolle Thatsache vor, dass in Wasser gelöste neutrale Seifen sich in hydrolytischer Dissociation befinden.

Wenn also bei der Resorption ein gelöstes Seifenmolekül in der Epithelzelle angekommen ist, zerfällt es in Folge der fortwährend an ihm sich vollziehenden Dissociation in Fettsäure und Alkali. Die Epithelzelle liefert der in statu nascendi befindlichen Fettsäure das Glycerin zur Synthese des Neutralfettes, und so ist ein Molekül Alkali frei geworden. Die vom Darme her nachdringenden, in Dissociation begriffenen Seifenmoleküle können an die in der Epithelzelle frei gewordenen Alkalimoleküle die von ihnen abtretenden Stearinsäuremoleküle abliefern. So würden die Fettsäuren fortwührend aus dem Darm in die resorbirenden Ejpithelzellen übertreten, ohne dass das Alkali nothwendig mitzugehen brauchte. Die Stearinsäure ginge gleichsam von Hand zu Hand von einem Alkalimolekül zum folgenden in der Richtung des Gefälles. Inas ist auch eine mögliche Vorstellung, welche die Finrede heseitigt, dass zu wenig Alkali im Darme sei, um die Verseifung dos gesammten resorbirten Fettes zu erklären.

I iese Betrachtung gilt ebenfalls für die Resorption der gelösten, nicht verseiften Fettsäuren, weın man zugiht, dass die Lösung sehliesslich auch auf lockerer, d. h. in Dissociation verkehrender Bindung der Fettsäuren beruht.

Es gibt aber noch andere berechtigte Annahmen zur Beseitigung jener Schwierigkeit, worüber ich später handeln will.

\section{$\$$ 6. Ueber die Reaction der Flüssigkeit im Dünndarm.}

Die beschriebenen Versuche haben bewiesen, dass die Galle bei jeder Reaction erhebliche Mengen von Fettsäuren zu lösen vermag, vorausgesetzt, dass Oelsäure vorhanden ist, was ja unter regelrechten Ernährungsverhältnissen immer der Fall sein wird. Die lösende Wirkung, welche die Galle ausübt, ist allerdings bei Weitem am grössten bei alkalischer Reaction. 
Desshalb wird es von Wichtigkeit sein, zu untersuchen, welche Reaction im Dünndarme während der Fettverdauung vorbanden ist.

So sonderbar es klingt, diese Frage kann in befriedigender Weise nicht beantwortet werden. Denn zuverlässige Forscher melden Ergebnisse, die einander widersprechen.

Nach Bidder und $S c h m i d t^{1}$ ) reagirt die innere Oberfläche der Schleimhaut des Dünndarms bei Prüfung mit rothem Lakmuspapier unter allen Umständen alkalisch, der Inhalt des Dünndarms aber bei Pflanzenfressern sauer, bei Hunden alkalisch, besonders bei Fleisch- und Fettnahrung. Nur zuweilen soll bei Hunden dieser Inhalt sauer sein.

Ausdrücklich heben Bidder und Schmidt hervor, dass sie diese Untersuchung an Hunden, Katzen, Kaninchen und Schafen nicht bloss im nüchternen Zustande, sondern auch in verschiedener Zeit nach Aufnahme der Nahrung ausgeführt hätten. Die Thiere wurden durch Aetherinhalation oder Stranguliren getödtet und dann sofort nach Eröffnung der Bauchhöhle die Prüfung vorgenommen. Dann legten Bidder und Schmidt permanente Dünndarmfisteln an und untersuchten den ausfliessenden Saft ${ }^{2}$ ).

„Endlich haben diese Forscher einem jungen Hunde nach Er„öffnung der Unterleibshöhle beide im Duodenum mündende pan"kreatische Gänge unterbunden und zwischen Ligatur und Darm "durchschnitten; dasselbe geschah mit dem Ductus choledochus, um "auch die Galle vom Darmcanale auszuschliessen. Zugleich wurde "durch Anlegung einer Gallenblasenfistel der Galle ein Ausweg ge"öffnet und endlich in dem unteren Winkel der Unterleibswunde ndurch Befestigung einer Dünndarmfalte eine Darmfistel vorbereitet. "Die zur Bildung der Gallenfistel gebrauchte Hornplatte war bereits „am dritten und der durch die Darmwand geführte Draht am vierten "Tage nach der Operation ausgefallen. Galle wurde, wie schon "gleich nach der Operation, so auch von nun an täglich und regel"mässig aufgefangen; weil dagegen das Einführen einer elastischen "Röhre in die Darmfistel ausserordentlich schmerzhaft war und die "heraustretende Flüssigkeit um diese Zeit noch mit Fiter und Blut "vermischt erschien, so konnte das Auffangen des Darmsaftes erst

1) Bidder und Schmidt, Die Verdaungssäfte und der Stoffwechsel S. $263-272.1852$.

2) Bidder und Schmidt, a. a. O. S. 264, 265, 268, 271. 
„am achten Tage nach der Operation beginnen. Der aus der "Fistel freiwillig ausfliessende Darminhalt war nach "ler Beschaffenheit der genossenen Nahrung ver"schieden. Nachdem das Thier ein par Tage hindurch "nur Schwarzbrot genossen hatte, wurde aus der Fistel „ein mit Brotresten gemischtes, bräunliches und zum "Theil breiges Fluidum entleert, das sehr schwach "alkalisch reagirte und eine grosse Menge durch Jod "zu erkennender Amylonreste enthielt; auch Zucker "war nachuuweisen, konnte aber von dem Brot selbst "herrühren. Hatte der Hund dagegen Fleisch und "Lebersubstanz vom Rinde zur Nahrung erhalten, so "war die heraustretende grau-weisse Masse stark "alkalisch reagirend und enthielt bei mikroskopischer "Untersuchung eine sehr grosse Menge freien, beim "Erkalten gerinnenden Fettes.

Die Section ergab, dass der Abschluss der Galle und des Bauchspeichels von der Darmhöhle gelungen war.

"Aus der Darmfistel, welche übrigens an dem "oberen Theile des Dünndarmes, etwa am Uebergang "des ersten Drittels in das zweite, sich befand, hatte "also ausser dem in den Darm gelangenden Magen"inhalt in der That nur das Secret der Darmwand "heraustreten können. Die Geringfügigkeit des letateren "gab sich hier auch dadurchkund, dass selbst das Duo"denum, trotzseinerstarkentwickelten l) rüsenschicht, "eine eben nur feuchte Innenfläche darbot, und die "alkalische Reaction des Darmsaftes wurde hier um "so entschiedener dargethan, als der alkalische pankrea"tische Saft ausgeschlossen war, der sanre Mageninhalt dagegen „in's Duodenum einströmen konnte mond nichtsdestoweniger das "anf die Duodenalschleimhant applicirte rothe Lakmuspapier ${ }_{n}$ stark gebläut wurde. Uebrigens zeigte die Darmschleimhaut "durchgehends eine ganz normale Beschaffenheit, und von Entzündung, "Irritation und dergleichen bot sich nirgends auch nur eine Spur dar."

"Von diesem Thiere nun haben wir reinen Darm"saft aufgefangen, der nach dem Filtriren eine zäh"flüssige, fadenziehende, farblose und stark alkalische "Substanz darstellte." 
Diese Angaben gestatten keinen anderen Schluss, als dass bei den von $B$ idder und $S \mathrm{ch}$ id t eingehaltenen Versuchsbedingungen, die aber doch sehr vielfach verändert worden sind, die Schleimhautoberfläche des Dünndarmes allgemein alkalisch, der Inhalt bei Fleischund Fettuahrung alkalisch, bei Pflanzenfressern aber stets sauer reagirt.

Ganz anders lauten die Angaben von Dr. Th. $\mathrm{Cash}^{1}$ ), der im Laboratorium von C. Ludwig die Frage nach der Reaction des Dünndarminhaltes während der Fettverdauung näher untersucht hat.

Cash liess die Hunde hungern und fütterte sie dann mit einem Gemenge von sehr viel Fett, und etwas Stärke oder auch von Fett allein. Auch mit vollkommen von Fettsäuren befreitem Fett stellte Cash Versuche an. Die Thiere wurden - was gewiss sehr zweckmässig ist, durch Einspritzung von Curare in eine Halsvene getödtet, gewöhnlich vier Stunden nach Einnahme der Nahrung. "So oft ich "diesen Versuch ausfürte," sagt $\mathrm{C}$ as h, „ergab er mir stets dasselbe: "der Inhalt des Dünndarms vom Pförtner bis zum Blinddarm hin „reagirte überall deutlich sauer, und es schwammen auf der centri„fugirten Flüssigkeit jedes Mal Oeltropfen kleineren und grösseren "Calibers." ${ }^{2}$ )

Immanuel Munk ${ }^{3}$ ) sagt:

„Nun habe ich aber bereits vor fünf Jahren und unabhängig von "mir und ziemlich gleichzeitig $\mathrm{Cash}$ darauf aufmerksam gemacht, "dass bei Fleisch- und Fettfütterung der Dünndarmehymus oder „besser der Wandbelag der Dünndarmsehleimhaut (einen eigentlichen "oder breiigen Dünndarminhalt findet man in der Norm nicht) stets „saure Reaction zeigt und frühestens etwa 10 Zoll unterhalb des "Pylorus neutral wird und bis zum Blinddarm auch reutral bleibt "und nur in Ausnahmefällen im untersten Theil des lleum ganz "schwach alkalisch wird."

Immanuel Munk sucht durch Rechnung zu zeigen, dass die saure Reaction des Darminhaltes beim Hunde selbstverständlich ist. Darauf ist nur zu erwidern, dass im Dünndarm des Hundes bei Fettresorption stark alkalische Reaction vorkommt, wie es Bidder und Schmidt als Regel angeben.

1) Th. Cash, Du Bois-Reymond's Archiv von 1880 S. 323.

2) Th. Cash, a. a. O. S. 324.

3) I. Munk, Zeitschr. f. physiol. Chem. Bd. 9 s. 573. 
In leidlicher Uebereinstimmung mit $\mathrm{Cash}$ und $\mathrm{I}$. Munk sind die Angaben von Moore und Rockwood, welche diesem Gegenstand eine grössere Untersuchung an 16 Hunden gewidmet haben.

Ihr Ergebniss ist, dass der Inhalt der oberen zwei Drittel des Dünndarms während der Fettverdaung sauer, der des letzten Drittels alkalisch reagirt gegen Lakmus. Fine besondere Angabe über die Reaction der Oberfläche der Schleimhaut fehlt, was wohl darin seinen Grund hat, dass die beiden Forscher auch diese im oberen Abschnitt des Dünndarms sauer fanden.

Moore und Rockwood haben bei der Prufung der Reaction als Indicatoren noch Phenolphthalë̈n und Methylorange angewandt. Sie finden, dass der Inhalt des Dünndarms vom Pylorus bis zum Coecun überail sauer gegen Phenolphthaleĩn reagirt. Nach diesen Forschern ist also in den oberen zwei Dritteln des Dünndarms s a u r e Reaction gegen Lakmus und Phenolphthaleïn, im unteren Drittel aber alkalische Reaction, wenn man mit Lakmus, saure, wenn man mit Phenolphthalein pruft. Zur Erklärung moinen Mo o re und Rockwood, dass wegen der sehr schwach sauren Natur des Phenolphthaleins die vorhandene freie Kohlensäure bereits genüge, um die Wirkung des kohlensauren Natriums zu unterdrüeken. Ich habe nun den Inhalt des unteren Drittels des Iünndarms heftig ind länger gekocht, um die Kohlensäure auszutreiben. Bei der dann erfolgten Prüfung tritt aber obensowenig die alkalische Reaction gegen Phenolphthaleïn auf. Folglich ist die Kohlensälire die wesentlich hier in Betracht kommende Ursache nicht. -- Ich nahm nun eine verdünnte Lösung von Natriumearbonat, setzte cinen Tropten der schwach gelblichen Lösung des l'henolphthaleïns hinzu und erhielt prachtvolle Röthung; dann nahm ich dieselbe Lösung von Natriumearbonat, fügte ein wenig Oelä̈ure hinzu und schüttelte, so dass bimulsion entstand. Fin Zusatz von Phenolphthalein brachte jetzt keine Röthung mehr hervor. Offenbar sind es also schwache orcanische Säuren, wahrscheinlich die leicht lösliche Oelsäure, welche die Wirkung des Natriumcarbonates auf das Phenolphthaleïn aufheben.

Methylorange ergab nach Moore und Rockwood in den oberen zwei Dritteln des Dünndarmes alkalische, Lakmus saure Reaction. Diese Forscher leiten dies daraus ab, dass in den oberen zwei Dritteln des Dümdarms vorhandene schwache organische Säuren wohl Lakmus, nicht aber Metbylorange beeinflussen.

Damit bleibt aber der Widerspruch bestehen, dass nach Bidder 
und Schmidt rothes Lakmuspapier beim Hunde durch den Saft des Dünndarms bei Fleisch- und Fettnahrung gebläut, nach $\mathrm{Cash}$, I. Munk, Moore und Rockwood aber blanes Lakmuspapier geröthet wird.

Ohne jeden Zweifel sind alle Angaben richtig. Es handelt sich darum, die Bedingungen für den Eintritt der alkalischen sowie der sauren Reaction festzustellen.

Es war mein Wunsch, durch eigene Versuche eine Erklärung der Widersprüche zu suchen.

\section{Versuch 25 .}

Ein Hund von $7 \mathrm{~kg}$ hungert 60 Stunden, erhält Morgens $6 \mathrm{Uhr}$ $400 \mathrm{~g}$ klein gemahlenes Kuhfleisch + $50 \mathrm{~g}$ Schweinefett. - Um 10 Uhr 15 Min subcutane Einspritzung von 0,04 g Morph. muriatic. Bauch geöffnet, sofort Pylorus unterbunden, dann Ende des Dünndarms, endlich noch ein Unterband da, wo das Ende des zweiten Drittels des Dünndarms in das dritte Drittel übergeht. Dann wird das Thier durch Durchschneidung der Halsgefässe getödtet.

Die oberen Drittel des Dündarms sind leer, die Oberfläche der Schleimhaut mit einem weissen Belag überzogen; sie zeigt überall gegen Lakmus stark alkalische Reaction. Das letzte Drittel des Dünndarms ergibt auch alkalische Reaction, die besonders gegen das Ende stärker hervortritt. In diesem Theile findet sich einige bräunliche, stark alkalische Flüssigkeit, die gegen Phenolphthalein nicht alkalisch reagirt. Im Dickdarm liegt dicklicher Koth mit überall alkalischer Reaction.

Die Länge der oberen zwei Drittel des Dünndarms war $2 \mathrm{~m}$, die des unteren Drittels $1 \mathrm{~m}$, die des Dickdarms $24 \mathrm{~cm}$.

Dieser Versuch ist eine Bestätigung der Angaben von Bidder und Schmidt. Er wurde angestellt in Gegenwart der Herren Dr. Max Bleibtreu und Dr. Josef Nerking.

\section{Versuch 26.}

Hund von $51 / 2 \mathrm{~kg}$ Gewicht. - Erhält nach 24 stündigem Hunger Morgens 6 bis $6^{1 / 2}$ Uhr $400 \mathrm{~g}$ gemahlenes Kuhfleisch $+50 \mathrm{~g}$ Schweineschmalz. Er wird nicht narkotisirt aufgebunden, Abdomen in Linea alba geöffnet und der Dünndarm wieder rasch mit Klemmen an den drei bezeichneten Stellen geschlossen. Thier getödtet $3^{1 / 2} \mathrm{Uhr}$ Nachmittags. 
Eine kleine Menge dicklicher, bräunlicher Flüssigkeit im oberen Abschnitt. Ueberall, auch auf der Schleimhaut nach Abtupfen saure Reaction. Im letzten Drittel des Dunndarms ist Inhalt und Schleimhautoberfläche alkalisch gegen Lakmus.

Dieser Versuch ist also eine Bestätigung von Moore und Rockwood.

Meine beiden Versuche widersprechen einander ebenso, wie die von Bidder und Schmidt denen von Moore und Rockwood entgegenstehen.

Es ist folglich gewiss, dass der Inhalt des Dünndarms je nach den Umständen sowohl sauer als alkalisch reagiren kann.

Welehes sind aber diese bestimmenden Umstände? Obne leugnen zu wollen, dass hier eine neue, umfassende Untersuchung eingreifen muss, glaube ich doch bereits jetzt eine krklärung geben zu können, die jener wenigstens als Richtschnur zu dienen geeignet ist.

Hier hebe ich zuerst hervor, wobei ich noch von den Pflanzenfressern absehe, dass fast alle Versuche, bei denen die saure Reaction im Dünndarm auftritt, solche sind, bei denen absichtlich grosse Fettmengen der Nahrung zugesetzt waren, weil man die Physiologie der Verdaung und Resorption der lette untersuchen wollte. Dabei sieht man, dass es glcichgültig ist, ol nehen dem Fett nur Stärke oder auch gar nichts weiter ( $\mathrm{Cash}$ ) gefüttert wird, oder ob neben dem Fett Flejsch gereicht wird, wie in meinem Versuche 26 und wahrscheinlich allen Versuchen von Moore und Rockwood. Daraus folgt mit grosser Wahrscheinlichkeit: die Zufuhr grosser Fettmengen in der Nahrung bedingt saure Reaction des Dünndarms.

Denn einnal werden nach Th. Cash und Franz Volhard die neutralen Fette schon in Magen zum Theile gespalten. Im Dünndarm setzt sich mit vermehrter Kraft diese Spaltung unter dem Einflusse verschiedener Fermente und Enzyme fort. Hierdurch wird begreiflich, dass nach Moore und Rockwood die saure Reaction vom Pylorus nach der Mitte des Dünndarms zunimmt, obwohl doch fortwährend neuer alkalischer Darmsaft und Bauchspeichel hervorquillt, um die Säuren zu sättigen. Durch meine mitgetheilten Versuche hat man aber erkannt, welche starke Verseifung der Stearinsäure und Palmitinsäure unter der Mithülfe der Oelsäure und Galle der Zutritt des kohlensauren Natrons veranlasst. Je reichlicher 
also die Menge der im Dünndarm auftretenden fetten Säuren sich geltend macht, um so schneller wird das Alkali der Soda verbraucht, also die eigentliche Ursache der alkalischen Reaction beseitigt. Weil in den oberen zwei Dritteln des Dündarms der grösste Reichthum an Galle, Fettsäuren und Soda ist, muss hier die stärkste Verseifung und Lösung der Fettsäuren stattfinden. In den letzten Abschnitt des Dünndarms gelangen die noch nicht resorbirten Ueberbleibsel der Fettsäuren nebst einer geringeren Menge von Galle und der Darmwand entstammender Soda, wesshalb hier kein so starker Verbrauch an Soda stattfindet, also die Reaction länger alkalisch bleiben kann, bis sie endlich auch hier in die saure umschlägt.

So erkläre ich mir auch den scheinbaren Widerspruch in meinen beiden eigenen Versuchen. Bei dem einen tödtete ich den Hund vier Stunden nach Einnahme des Fettes und fand alkalische Reaction im Dündarm, weil das Alkali dureh die Verseifung noch nicht ganz aufgebraucht war. - Bei dem anderen Versuch tödtete ich den Hund aber erst neun Stunden nach Zufuhr einer relativ etwas grösseren Fettmenge. Diese mehr als doppelt so lange Zeit hat genügt, um wenigstens in den oberen zwei Dritteln des Dünndarms das gesammte Natriumearbonat zur Verseifung zu verbrauchen, so dass die noch vorhandenen organischen Säuren nunmehr die saure Reaction veranlassten.

Sobald die saure Reaction einmal eingetreten ist, fäbrt natürdie Schleimhaut fort, Natriumcarbonat dem sauren Chymus zuzuführen. Dieses wird nun aber sofort zur Verseifung verbraucht, und so bleibt die saure Reaction weiter bestehen, bis alle Fettsäuren resorbirt sind.

$\mathrm{Ob}$ also im Dündarm saure oder alkalische Reaction vorhanden ist, hängt ab von dem. Verbältniss der Geschwindigkeit der Verseifung zu der der Absonderung von Natriumearbonat.

Ist nun - so wollen wir fragen - die Annahme gestattet, dass bei saurer Reaction des Dünndarm-Inhaltes kein kohlensaures Natrium in Lösung ist? Ich habe durch die mitgetheilten Untersuchungen gezeigt, dass Oelsäure, mit einer äquivalenten Menge von Soda emulgirt, bei $37^{\circ} \mathrm{C}$. im Laufe einer Stunde nur spurweise Verseifung bedingt. Neben einander bestehen die organische Säure und die Soda, ohne auf einander durch Wechselzersetzung zu wirken, und das ist sogar der Fall, wenn Galle gleichzeitig vorhanden ist, welche die Oelsäure neben der Soda in wässrige Lösung bringt. Die Oelsäure kann also die Kohlensäure aus der 
Soda nicht austreiben. Die Oelsäure reagirt aber, direct auf blaues Lakmus gebracht, wie ich mich überzeugte, sauer. Löst man im Reagensglas Oelsäure in Aether und bringt ein Stückehen Reagenspapier hinein, so färbt sich dasselbe bei einigem Abwarten roth; sofort, wenn man den Aether auf das trockene Reagenspapier giesst. Nun reagiren äquivalente Mengen von Oelsäure und Sodalösung bei Gegenwart neutraler Galle alkalisch. Sind aber gleichzeitig grössere Mengen von Stearinsäure und Palmitinsäure vorhanden, so wird die Soda schnell zur Verseifung der letzteren verbrateht, so dass schliesslich die freie, nicht verbrauchte Oelsäure und ausgetriebene Kohlensäure saure Reaction der Flüssigkeit bedingen muss. Man sieht ja beim Titriren von Sodalösungen mit Schwefelsäure oder Salzsäure, dass ein Punkt kommt, in dem die Flüssigkeit sauer reagirt, aber beim Kochen wieder alkalisch wird. Daraus folgt, dass Natriumearbonat in einer durch organische Säuren, sogar nur durch Kohlensäure sauren Flüssigkeit vorhanden sein kann. Wäre also die saure Reaction des Dünndarm-Inhaltes durch Fettsäuren mit Oelsüure und Kohlonsâure bedingt, so würde sicher in der sauren Flüssigkeit fortwährende Verseifung stattfinden wegen der Gegenwart von Soda. Ich hätte hier aluch noch die schwachen Gallensäuren heranziehen können, wenn ich nicht glaubte, dass ihre Austreibung dureh die Fettsäuren ciner ernenten l'rüfung bedürtig wäre.

Eine lsurze Bemerkung ist mit Rüeksiclit auf die Iflanzenfresser nöthig, wenn es wahr ist, dass nach Biddor und Schmidt zwar nicht die Schleimhaut, wohl aher der Dünndarm-Inhalt immer sauer ist. Da man nicbt annehmen kann, dass die Nahrung dieser Thierclassen immer reich an Fett ist, so muss die saure Reaction des Chynus eine besondere Ursache haben, die vielleicht in der sauren Gährung der Kohlehydrate liegt. Gross kamm relativ aher dicse Säurebildung nicht veranschlagt werden, weil die Oberfläche der Schleimhaut in Dünndarm der Pflanzenfresser stets alkalische Reaction darbieten soll. Darum erwächst auch für die Möglichkeit der Verseifung keine wesentliche Schwierigkeit für die Erklärung.

\section{\$ 7. Erklärung der Fettresorption anf Grund der gewonnenen Ergyebnisse.}

Die beschriebenen Versuche haben erwiesen, dass $100 \mathrm{ccm}$ Galle vom Ochsen in runder Summe $15 \mathrm{~g}$ Fettsäuren in wasserlösliche Form zu briugen vermögen, wenn man ein Gemenge von gleichen 
Theilen Oelsäure einerseits und Palmitinsäure oder Stearinsäure andererseits nebst der äquivalenten Menge von Soda anwendet. Für die reine Oelsäure ist bei Gegenwart von Soda der Löslichkeitscoëfficient noch nicht bestimmt. Ich habe in den oben beschriebenen Versuchen nur bewiesen, dass $100 \mathrm{ccm}$ Galle mindestens $10 \mathrm{~g}$ Oelsäure bei Gegenwart der äquivalenten Menge von Soda zu lösen vermögen. Durch besondere Versuche, die ich nicht mitgetheilt habe, fand ich, dass $100 \mathrm{cem}$ Galle bei Gegenwart der äquivalenten Menge von Soda $20 \mathrm{~g}$ Oelsäure nicht mehr zu lösen vermögen. Die nicht gelöste und nicht verseifte Oelsäure lässt sich aus dem Gallengemisch nicht so abfiltriren, wie das bei der nicht gelösten und nicht verseiften Palmitinsäure oder Stearinsäure möglich ist. Denn die Oelsäure bildet eben dann eine unendlich feine Emulsion, die durch alle Filter geht. Bedenkt man aber, wie sehr die freie Oelsäure und ihre Natronseife die festen Fettsäuren an Löslichkeit übertreffen, so muss man für sehr wahrscheinlich balten, dass ihr Löslichkeitscoëfficient nicht sehr verschieden von den mit Oelsäure gemischten festen Fettsäuren sein werde.

Meine Versuche zeigen, dass im Gegensatz zu dem, was meistens bis jetzt angenommen worden ist, die Wasserlöslichkeit der Oelsäure keineswegs in erster Linie durch Verseifung, sondern wesentlich durch Lösung ohne Verseifung erzielt wird; dass ferner bei den festen Fettsäuren durch Verseifung mehr als durch Lösung geleistet werden kann.

Hieraus lässt sich noch kein sicherer Schluss ziehen, ob die Fettsäuren in grösserer Menge als freie oder als verseifte resorbirt werden.

Denn in dem Darme findet fortwährend sehr starke Resorption statt, so dass es zu einer Anhäufung gelöster Fettsäuren schwerlich kommt. Bei meinen Versuchen im Glase werden die zur Lösung gebrachten Fettsäuren nicht durch Resorption fortgeschafft, häufen sich an, bilden gesättigte Lösungen und erschweren so das rasche Fortschreiten des Lösungsgeschäftes ohne Zweifel, gerade so wie bei der künstlichen Pepsin-Verdauung alsbald Stillstand eintritt, weil die Lösung mit Pepton gesättigt ist.

Wenn ich zu einer Erklärung der Fettresorption auf Grund der gefundenen Ergebnisse übergehe, so möchte ich zuerst den Weg der Beweisführung innehalten, welcher bisher als berechtigt fast allgemein anerkannt worden ist.

Es handelt sich um die Frage, ob die in $24 \mathrm{Stunden}$ in den 
Dünndarm ergossene Menge der Galle und des Natriumcarbonates zur Ueberführung der thatsächlich resorbirten Fette in wässrige Lösung genügt.

Hier ist denn zuerst von Im ma n e l M unk behauptet worden, dass die im ganzen Körper enthaltenen Mengen von Alkali zur Verseifung alles resorbirten Fettes nicht ausreichen.

Die Bedeutungslosigkeit der Betrachtung von Immanuel M unk erhellt leicht aus folgender Erwägung.

Sobald die im Dünndarm entstandenen Seifen von den Epithelzellen der Schleimhaut resorbirt sind, zerfallen sie sofort in freies Alkali und fette Säure, welche in statu nascendi sich mit Glycerin wieder zu Neutralfett vereinigt. Da überall in den Zellen freie Kohlensäure ist, hat es keine Schwierigkeit zuzugeben, dass Natriumcarbonat ebenso wie Neutralfett regenerirt wird, aus denen im Darm die resorbirte Seife entstand. Weil nun die vom Darme resorbirten, in Wasser löslichen Stoffe rasch von den Blutgefässen aufgesogen werden, muss dies auch für das Natriumcarbonat gelten, welches in den Säften der Epithelzelle gelöst ist. Dadurch wird aber die zur Verseifung im Darmcanal verbrauchte Soda nach der Resorption dem Blutstrome als wieder erzente Soda sofort zuruckerstattet, um die Drüsen der Schleimhaut des Dünndarms, sowie das Pankreas und die Leber auf's Neue mit Alkali zu versorcen.

Es ist ein Naturgesetz, dass alle Organe sich der Grösse des Bedürfnisses anpassen, und desshalb nicht gewagt, daran zu denken, dass in dem Maasse, als der Verseifungsvorgang im Darme an Stärke wächst und Alkali verbraucht, von den Drüsen mit vermehrter Kraft Alkali in den Darm zum Ersatz nachgeliefert wird. Wieviel während der Fettverdauung der unversehrte Darm auf diese Weise Alkali zu liefern vermag, wissen wir nicht, weil eine von unscrem Standpunkte aus durchgeführte Untersuchung nicht vorliegt, die auch sehr grosse, gegenwärtig unüberwindliche Schwierigkeiten zu überwinden haben würde.

Die hier dargelegte Erklärung, die sich durch ihre Einfachbeit empfiehlt, zeigt, dass eine verhältnissmässig geringe Menge von Alkali genügt, um alles Fett zu verseifen, weil das Alkali einen fortwährenden Kreislauf durchmacht.

Die Behauptung, dass es an Alkali fehle, um die Fette aus dem Darme als Seifen zur Resorption zu bringen, ist demnach von keinem Gewicht und auch nicht durch Thatsachen bewiesen.

Nach den Untersuchungen von Pettenk ofer und Voit, von 
mi ir und von Schöndorff ist das Nahrungsbedürfniss eines Hundes von $30 \mathrm{~kg}=2,066 \mathrm{~N}$ auf $1 \mathrm{~kg}$, wenn ich meine Zahlen ${ }^{1}$ ) $\mathrm{zu}$ Grunde lege. Da nach meiner Berechnung $1 \mathrm{~g} \mathrm{~N}=26,7$ W.-E., so hat man $1 \mathrm{~kg}=55,162 \mathrm{~W}$.E., also für $30 \mathrm{~kg}$ als Bedürfniss 1654,86 W.-E.

Würde der Hund von $30 \mathrm{~kg}$ sein ganzes Nahrungsbedürfniss mit Fett befriedigen, woran unter normalen Verhältnissen doch gar nicht zu denken ist, so müsste er demgemäss $174 \mathrm{~g}$ Fett in 24 Stunden resorbiren.

Nach Hejdenhain's Untersuchungen bildet ein Hund von $30 \mathrm{~kg} 981$ bis $1083 \mathrm{~g}$ Galle in 24 Stunden. Setzen wir in runder Summe $1000 \mathrm{ccm}$, so würden diese nach unserer Untersuchung etwa $155 \mathrm{~g}$ Fett in wasserlösliche Form zu verwandeln vermögen. Meine Zahlen sind allerdings nicht mit Hundegalle, sondern mit Ochsengalle gewonnen. Nach den Bestimmungen von Moore und Rockwood löst aber die Hundegalle die Fettsäuren sehr viel reichlicher. als dies die Ochsengalle vermag.

Im Uebrigen versteht es sich ja von selbst, dass es sich hier nur um ein ungefähre Schätzung handelt.

Wie man erkennt, genügt also die in 24 Stunden abgesonderte Menge der Galle, um bei Gegenwart der hinreichenden Menge von Soda die normalen Mengen von Nahrungsfett in wasserlöslicher Form zur Resorption zu bringen.

Nun wird allerdings behauptet, dass ein Hund von $30 \mathrm{~kg}$ sehr viel mehr Fett, als seinem Bedürfniss entspräche, zu resorbiren vermöge - nämlich bis zu $300 \mathrm{~g}$. - Ich glaube, dass dieser Punkt nicht so genügend untersucht ist, wie es nothwendig wäre, wenn ihm eine grundsätzliche Bedeutung zuerkannt werden soll. Sollte aber diese Behauptung sich als wahr herausstellen, so würde ich darin nur ein weiteres Beispiel erkennen für die Thatsache, dass der Organismus die Fähiglseit, sich gesteigerten Anforderungen anzupassen, in ausgezeichneter Weise besitzt. Wir sehen ja, dass nach Ausrottung einer Niere die übrig bleibende die doppelte Arbeit übernimmt. Für unseren Fall bedeutungsvoller ist, dass nach Ausrottung der das Fett mächtig spaltenden bauchspeicheldrüse die Fettspaltung im Darme fast ungeschwächt weiter in das Werk gesetzt wird, weil wohl schnell andere Drüsen zum Ersatz eintreten.

Bei den bisherigen Betrachtungen sind wir von der gebräuch-

1) Dies Archiv Bd. 52 S. 49. 1892. 
lichen Annahme ausgegangen, dass in dem Maasse, als grössere Fettmengen zur Resorption gebracht werden sollen, auch grössere Gallenmengen erfordert werden. Dieser Standpunkt ist aber schwerlich der richtige.

Zuerst erinnern wir uns, dass die Bestandtheile der Galle zum sehr grossen Theile gar nicht resorbirt werden, und dass die Galle, wie ich bei Diffusiousversuchen gesehen habe, dureh Pergamentpapier ausserordentlich schwer und durch Collodiumhänte, wie es schien, gar nicht diffundirt.

Unter Beihülfe der Galle und Soda werden die Fette in Seifen übergeführt, weil die Galle mit Soda die Fettsäuren löst. Fest verbindet sich chemisch die Galle weder mit Fettsäuren noch mit Soda. Wenn die gebildeten Seifen in Folge der Resorption durch die für sie leicht durehlässige Basalmembran der resolbirenden Cylinderzelle getreten sind und die Galle in der Darmhöhle zurückgeblieben ist, vermag sie für die durch Verseifung und Resorption fortgeschafften Fettsäuren neue zu lösen, so dass also eine kleine Venge von Galle die Verseifung sehr grosser Mengen von Fettsäuren zu vermitteln befähigt ist.

Diese Erörterung zeigt, dass für das Verständuiss der Resorption fast beliebig grosser Seifenmengen keine Schwierigkeit vorliegt.

Es fragt sich, wie sich die Sache für die nicht verseiften, abcr gelösten Fettsäuren verhält. Dass die Lösung derselben in Galle und besonters in Gaile + Soda für den Verseifungsvorgang von wesentlicher Bedleutung ist, habe ich bewiesen, und man könnte desshalb denken, dass die Lösung der Oelsäure und festen Fettsäuren nur der Verseifung halber in Betracht komme, da alles Fett nur in der Form der Seife resorbirt werde. Es gibt keine Thatsache, welche die Frage entscheidet. Die im Chylusfett vorkommenden freien Fettsäuren könen schr wohl aus den resorbirten neutralen Seifen abgeleitet werden. Ws lässt sich denken, dass bei Zufuhr reicher Seifenmengen die Epitholzelle für alle entstehenden Fettsäuren das zur Synthese nothwendige Glycerin nicht ganz zu liefern vermag; dann wird das Chylusfett freie Fettsäuren enthalten müssen.

Uebrigens würde das Vordringen geringer Gallenmengen in die Epithelzelle auch den Uebergang grösserer Mengen gelöster Fettsäuren erklären, weil diese eben an die Galle und Soda nicht chemisch fest gebunden sind, sondern wohl nur in Dissociationsverkehr stehen. 


\section{$\$ 8$. Ergebnisse.}

1. $100 \mathrm{ccm}$ frische, also alkalische Ochsengalle lösen 4 bis $5 \mathrm{~g}$ Oelsäure. Denselben Werth liefert neutralisirte oder schwach angesäuerte Galle.

2. $100 \mathrm{ccm}$ frische Ochsengalle lösen mehr als $10 \mathrm{~g}$ Oelsäure, wenn gleichzeitig eine der Oelsäure äquivalente Menge von Sodalösung hinzugefügt wird. Neuere an heissen Tagen angestellte Bestimmungen ergaben nur etwas über $7 \mathrm{~g}$.

3. Mischt man ohne Galle $5 \mathrm{~g}$ Oelsäure mit einer verdünnten äquivalenten Sodalösung und erwärmt 7 bis 24 Stunden auf $37^{\circ} \mathrm{C}$., so werden nur 17,3 bis $19 \%$ der Fettsäure verseift.

4. Mischt man $5 \mathrm{~g}$ Oelsäure auf $50 \mathrm{ccm}$ Galle mit einer äquivalenten Menge von Sodalösung, so werden in 19 bis 24 Stunden nur 9,9 bis $13,8 \%$ verseift. Durch Galle wird also die Verseifung der Oelsäure mit Soda durchaus nicht gefördert.

5. $100 \mathrm{ccm}$ Galle lösen bei Gegenwart der äquivalenten Menge Soda mehr als 8,6 bis $9,4 \%$ Oelsäure in ganz kurzer Zeit, ohne dass es sich um Verseifung handelt.

6. Wenn Stearinsäure mit einer äquivalenten Menge verdünnter Sodalösung auf $37^{\circ} \mathrm{C}$. erwärnt wird, so ist erst nach etwa 4 bis 5 Tagen eine Spur von Verseifung zu bemerken.

7. Wenn Stearinsäure mit Oelsäure und einer äquivalenten Menge verdünnter Sodalösung auf $37^{\circ} \mathrm{C}$. erwärmt wird, so vollzieht sich eine sebr erhebliche Verseifung in derselben Zeit, welche bei Abwesenheit der Oelsäure nur zu spurenhafter Verseifung führt.

8. Wenn man Versuch 6 und 7 in der Art wiederholt, dass Galle zugefügt wird, bemerkt man eine viel kräftigere und schnellere Verseifung. Aber auch hier hat die Gegenwart der Oelsäure einen ausserordentlich fördernden Finfluss auf die Verseifung.

9. $100 \mathrm{ccm}$ Galle vermögen im Reagensglas nach Zusatz von $10 \mathrm{~g}$ Stearinsäure und $10 \mathrm{~g}$ Oelsäure und der äquivalenten Menge einer verdünnten Sodalösung etwa $15 \mathrm{~g}$ Fettsäure in wasserlösliche Form überzuführen.

10. Neutrale, in Wasser gelöste Seifen werden durch viel Wasser gefällt, wobei freie Fettsäuren auftreten, die noch unzersetzte Neutralseifen einschliessen. Das Neutralsalz der Fettsäuren befindet sich im Wasser gelöst im Zustande hydrolytischer Dissociation.

11. Während der Fettresorption ist die Reaction des DünndarmInhaltes und seiner Schleimhaut bald alkalisch und bald sauer. 